\title{
A Research into the Amyloclastic Secretory Capacities of the Embryo and Aleurone Layer of Hordeum with Special Reference to the Question of the Vitality and Auto-depletion of the Endosperm.
}

\author{
PART II.
}

\author{
BY
}

F. STOWARD.

Contents of Part II.

V. On the Partial Suppression of the Amyloclastic Secretory Function of The Aleurone Layer.

PAGE

VI. The Behaviour of the Inner Endosperm Tissue towards Anaesthetic Reagents: the Probable Non-possession of Vitality by this Tissue . Iigo

VII. Starch-Liquefying and Saccharifying Properties of (I) Embryo and Aleurone-layer Secretions, (2) Extracts of Endosperms and InNer ENDOSPERMS

VIII. The Influence of Various Carbohydrates on the Secretion of Amylase by the Embryo and Aleurone. Layer

IX. Investigation of the Amylase Content of the Scutella of Barley Seedlings i i67

X. The Secretion of Cytase by the Embryo and Aleurone layer . . . il 69

XI. Influence of the Embryo on the Augmentation of Amylase by the Inner ENDOSPERM • • • • • • • • • • • • • • II75

XII. The Inactivation of the Amylase of Ungerminated Barley . . . II 76

XIII. The Inadmissibility of Copper Sulphate as a Sterilizing Agent • • ir8i XIV. Investigation of Material by the Auto- and Papain-digestion Methods. il 82 XV. Investigation of Amylase Content of the Tissues of Tropaeolum by Direct, Auto-, and Papain-digestion Methods . . . . . . ilg7 XVI. Summary of Conclusions . . . . . . . . . . . . I 200

V. ON the Partial SUPpression of the Amyloclastic Secretory Function of the Aleurone Layer.

$\mathrm{T}$ the foregoing sections the methods of eliminating the functional in1 fluence of the aleurone layer rest on its actual removal (by filing or cutting it off), or on the annihilation of the secretory mechanism by the action of anaesthetic reagents which by prolonged contact eventually cause the death of this tissue.

There remains yet another method of suppressing wholly, or at least partially, its secretory functions, namely, by conducting culture experiments

[Annals of Botany, Vol. XXV. No. C. October, Igys.] 


\section{48 Stoward. - Amyloclastic Secretory Capacities of the}

under partial anaerobic conditions, with simultaneous partial removal of the aleurone layer itself.

In the following experiments the dorsal portion of the layer was completely removed before the establishment of the cultures. The objects (Experiment I) were cultivated in the customary manner under aerobic conditions ; in the remaining numbers of the series, under anaerobic conditions, the objects were embedded in the lowest part of a column of agar medium, having a uniform depth of $10 \mathrm{~cm}$., and contained in test-tubes, the mouths of which were:closed with loosely fitting cotton-wool plugs.

\section{TABLE XXI.}

\section{Cultures of Endosperms deprived of the Dorsal Portion of THEIR AlEurone LAYers ON $0.8 \%$ Agar, With AND Without Mineral SALTS.}

Chilian barley. Seeds, 48 hours absolute alcohol, 48 hours water. Culture period, 68 days.

\begin{tabular}{|c|c|c|c|c|c|}
\hline Objects. & Culture medium. & $\begin{array}{l}\text { Conditions of } \\
\text { experiment. }\end{array}$ & $\begin{array}{r}A m j \\
\text { Direc } \\
(e q 2\end{array}$ & $\begin{array}{l}\text { per } 20 \\
\text { cts. } \\
\text { Papain. }{ }^{1} \\
\text { ent to } m g .\end{array}$ & $\begin{array}{l}\text { Reduci } \\
\text { sugars } \\
\text { medium } \\
\text { of } \mathrm{Cu} \text {.) }\end{array}$ \\
\hline $\begin{array}{l}\text { Io endosperms deprived of } \\
\text { dorsal aleurone laver (whole) }\end{array}$ & $0.8 \%$ agar & aerobic & - & - & $43^{2}$ \\
\hline $\begin{array}{l}\text { 2. } 10 \text { endosperms deprived of } \\
\text { dorsal aleurone layer (halved) }\end{array}$ & $0.8 \% \mathrm{ag}$ & ana & I68 & 4220 & \\
\hline $\begin{array}{l}\text { 3. Io endosperms depri } \\
\text { dorsal aleurone layer (h }\end{array}$ & $0.8 \%$ agar-mineral & ana & 168 & 4810 & \\
\hline $\begin{array}{l}\text { 4o endosperms deprived of } \\
\text { dorsal aleurone layer (halved) }\end{array}$ & $0.8 \%$ agar & ana & 168 & 219 & \\
\hline 5. Io endosperms deprived of & $0.8 \%$ agar & anaerobic & 337 & 3544 & \\
\hline
\end{tabular}

In Experiment $I$ at its termination there remained in the majority of instances the ventral portion of the aleurone layer only, the starch contents and cell-structures of the inner endosperm having almost completely disappeared.

Those in which a starchy residue of inner endosperm still persisted showed on microscopical examination the phenomena customarily presented by endosperms undergoing digestion, namely, deeply and extensively eroded starch grains, and totally disorganized and disintegrated cell-walls and cytoplasmic débris.

On desiccation for a few hours at $30^{\circ} \mathrm{C}$. the resistant aleurone-layer tissue only remained, and therefore no estimation of its amylolytic activity was undertaken.

This experiment is of interest because it shows distinctly that the ventral portion of the aleurone layer resembles the dorsal portion (provided the experiment is sufficiently prolonged) in possessing an intense power of depleting the inner endosperm. But unquestionably, during both natural germination and under the artificial conditions described in these experiments, the secretory function of the aleurone layer appears to be more

1 Amylase in objects determined by direct and papain digestion methods.

2 Reducing sugars in medium estimated directly.

9 Objects in Experiments 2-5 halved longitudinally to increase extent of diffusion surface. 
readily induced and to exhibit its powers more actively in its dorsal portion.

In the anaerobic series of experiments (Experiments 2, 3, \&c.), the early suppression and eventual annihilation of the aleurone-layer secretory mechanism is obvious from a consideration of the lower amounts of reducing sugars present in the media in these experiments; in fact, comparison of the amounts of reducing sugars is a far more accurate criterion and measure of the relative depletive capacities possessed by two tissues, than is comparison of their amylolytic augmentative capacities.

As already insisted, the demonstration of this latter capacity, unless it can be shown that the amylases derived from the aleurone layer and inner endosperm are of equal value in their power of attack upon barley starch under normal conditions of germination, loses much of its importance and value.

The objects in these anaerobic experiments retained their original mass and form, and there was, as shown by a searching macro- and microscopical examination, an almost entire absence of evidence indicative of digestive changes. In all, as was to be anticipated, there were examples of eroded starch grains, produced no doubt prior to the complete inhibition of the secretory functions of the aleurone layer. The characteristic brown colour developed invariably in the functioning aleurone layer, especially at its exposed margins, was wanting.

Lastly, although direct digestion of the objects shows the existence of small amounts of free amylase, thus pointing to its inactivation or destruction as the result of its activity, yet papain-digestion indicates the presence of very considerable amounts of 'latent' amylase. The inference to be derived from these facts is that the reducing sugars found result from the more active aleurone-layer secretion at an early epoch in the course of the experiments.

These series of experiments afford, on the one hand, convincing evidence of the effectiveness of the method of sterilization employed; not only did the cultures during this lengthy period of experiment remain absolutely sterile, but the employment of alcohol in place of $\mathrm{CuSO}_{4}$, as a sterilizing agent, obviates the troublesome source of confusion in experiments with endosperms to which reference will be made later. On the other hand they present an array of experimental data which renders it extremely difficult to avoid the conclusion that, during the germination process, starch dissolution and digestion (and, as we shall see later, cellulose digestion) are largely dominated by exercise by the aleurone-layer cells of their undoubted secretory functions. 


\section{The Behaviour of the InNer Endosperm Tissue towards Anaesthetic Reagents : the Probable Non-possession of Vitality By this Tissue.}

The views regarding the possession of vitality by the inner endosperm of barley are diametrically opposed.

Brown and Morris (loc. cit., Part I, p. 8co) claim that this tissue consists of non-living cells; Hansteen, and also Puriewitsch, contends that each amyliferous cell in the endosperm of the Gramineae is to be regarded as a living functionary unit. Bruschi (loc. cit.) states that the cells situated at the extreme periphery of the inner endosperm, and immediately subjacent to the aleurone layer, are probably living units.

Hansteen and Puriewitsch's claim rests, as we have seen, on an inadmissible method of proof. Bruschi's statement rests on a sounder basis, namely, cytological examination of the nuclei of the more peripherally situated amyliferous cells and the application of plasmolytic tests.

Evidence derived from a study of the respiratory capacity of this tissue (Stoward, loc. cit., Part I, p. 82I) does not permit of the clear definition of this function being due solely to either vital or enzymatic activity.

When an undoubtedly living organism, organ, or tissue is subjected to the action of an anaesthetic reagent for a sufficient length of time, ultimate annihilation of its functions ensues.

Experimental evidence has already been adduced showing that when isolated embryos and aleurone layers are anaesthetized, and the action of the anaesthetic is prolonged, the amyloclastic secretory function of the embryo is totally suppressed, and the same function of the aleurone layer never attains its original level-the appearance of enzyme in the external substratum in this latter case being attributed to the passive outward diffusion of pre-existent enzyme in the tissue, and to that formed during the progress of anaesthesia.

Demonstration of the manifestation of enzymatic activity by a given tissue furnishes, it is true, no criterion of the possession of vitality by the tissue.

The question assumes another aspect, however, in the case about to be treated, where the points to be discussed refer to the behaviour of the embryo, aleurone layer, endosperm, and inner endosperm, when exposed to the continued action of certain anaesthetic reagents. We have seen that the effect of anaesthesia on the aleurone layer is distinctly to diminish and lower its secretory capacity. Suppose endosperms and inner endosperms are similarly anaesthetized, and that it is found, after cultivation on gelatine medium and subsequent investigation of the medium and objects for amylase, that the amount of enzyme found in the case of anaesthetized endosperms is distinctly lower than that found in similarly constituted culture experiments with unanaesthetized endosperms, while the amount 
of amylase found in the case of anaesthetized inner endosperms is practically the same as that found in similarly constituted cultures with unanaesthetized inner endosperms, how are these results to be interpreted with regard to the question of the possession or otherwise of vitality by the inner endosperm?

\section{Cultures of endosperms and inner endosperms on gelatine media.}

In the following experiments, which furnish concrete examples of the foregoing proposition, either nitrobenzene or chloroform was plenteously mingled with the medium prior to placing the objects in it. It was necessary, on account of the volatility of chloroform, to make fresh additions of this reagent every twenty-four hours: nitrobenzene, being less volatile, proved to be an excellent reagent in experiments of this kind.

\section{TABLE XXII.}

Cultures of Endosperms and Inner Endosperms on $5 \%$ GelatineMineral Salts with Varying Concentrations of $\mathrm{KH}_{2} \mathrm{PO}_{4}$, in Presence of Nitrobenzene. I 8 days.

Chilian barley seeds. (I) Absolute alcohol, 48 hours; (2) water, 48 hours. Culture period

Exp.

Objects.

5 endosperms

5 inner endosperms

$"$ "
Concentration of $\mathrm{KH}_{2} \mathrm{PO}_{4}$ in

$\mathrm{P}_{3}$
$\mathrm{P}_{3}$
$\mathrm{P}_{1}$
$\mathrm{P}_{2}$

Amylase per 20 objects per hour in:Medium. Objects. Total. (equivalent to mg. of Cu.)

$\begin{array}{ccccc}2559 & - & - & 25 & 21 \\ 2349 & - & - & 0.00 & 0.00 \\ 2066 & 337 & 2403 & - & - \\ 2215 & 337 & 255^{2} & - & -\end{array}$

The amounts of amylase found in the culture media in the above series of experiments, it will be observed, are of practically the same order of magnitude. The fact is significant, because it shows that the direct result of the action of these anaesthetics is to suppress almost completely the secretory powers of the aleurone layer (Experiment I), and to reduce the endosperm, considered as a generator of amylase, to the level of the inner endosperm.

\section{TABLE XXIII.}

Cultures of Endosperms and InNer Endosperms on $5 \%$ Gelatine-Mineral Salts $\left(\mathrm{P}_{3}\right)$ in Presence of Chloroform.

Culture period, I 2 days. Chilian barley-objects prepared as below.

\begin{tabular}{|c|c|c|c|c|c|c|}
\hline \multirow{2}{*}{ Exp. } & \multirow{2}{*}{ Objects. } & \multicolumn{3}{|c|}{$\begin{array}{l}\text { Amylase per } 20 \text { objects } \\
\text { per hour in:- }\end{array}$} & \multicolumn{2}{|c|}{$\begin{array}{l}\text { Reducing sugars } \\
\text { per } 20 \text { objects in :- }\end{array}$} \\
\hline & & $\mathrm{Me}$ & & $\begin{array}{l}\text { Total. } \\
\text { uivalent }\end{array}$ & $\begin{array}{l}\text { Medium. } \\
\text { g. of Cu.) }\end{array}$ & \\
\hline & 5 inner endosperms & 2489 & $5^{2}$ & 3016 & - & 0.00 \\
\hline & ", & 2489 & 29 & & - & 0.00 \\
\hline & 5 endosperms & 886 & $95^{\circ}$ & 1836 & 85 & 0.00 \\
\hline
\end{tabular}

Experiment I. Inner endosperms prepared from endosperms steeped successively in (1) absolute alcohol, (2) water. $4^{8}$ hours in each reagent.

Experiment 2. Inner endosperms prepared from air-dried seeds \& steeped as in Experiment $\mathbf{I}$.

Experiment 3. Endosperms from air-dried seeds steeped as in Experiment $\mathrm{I}$. 
Comparison of the results shown in Tables XXII and XXIII above, with those of Tables XII, XIV, and XVI, demonstrates clearly that the augmentative capacity of anaesthetized inner endosperms is just as great, if not greater than that of inner endosperms not exposed to the action of the reagents mentioned. The rather higher results afforded by the chloroform experiments appear to suggest that this agent exercises a stimulative action.

A similar comparison made with reference to endosperms (see Tables XII, $\mathrm{XIV}$, and XVI), on the other hand, shows that the effect of anaesthetizing these objects is to lower their amyloclastic augmentative capacities.

The results of experiments with anaesthetized inner endosperms offer a distinct contrast to those yielded by the similarly treated embryos and aleurone layers in the experiments described in Section IV, while those derived from experiments with anaesthetized endosperms coincide with the experimental results referred to, in that there is a distinct lowering of the output of amylase.

The behaviour of the embryo, aleurone layer, and endosperm under the conditions described, which induce ultimate disorganization of the vital functions of the secretory tissues, is that of a living organism or tissue ; that of the inner endosperm, on the contrary, can hardly be ascribed to a tissue which consists indubitably of living units.

The view advanced by the author, based on these experiments, is that the inner endosperm of barley represents for the most part at least a non-living tissue.

The amounts of amylase found in the culture media of both the above series of experiments, it will be observed, are practically of the same order of magnitude if we exclude Experiment 3, Table XXIII.

This fact is significant because it shows that the direct and ultimate result of the action of these anaesthetics is to suppress completely the secretory powers of the aleurone layer, and to reduce the amyloclastic augmentative capacity of the endosperm to the level of that possessed by the inner endosperm. Accompanying this is the low production of reducing sugars in medium and objects (see Tables XXII, XXIII, and XV), and further, the important fact must be noted that in the endosperm experiments the starch grains of the endosperms, just as in the case of inner endosperms, show absolutely no signs of erosion, which, as we have repeatedly seen when the aleurone-layer secretory function is not interfered with, is the constant and invariable accompaniment of its activity.

The aleurone layer, moreover, is only removable from the subjacent tissue in these cases (endosperms) with difficulty, and its margins do not exhibit the conspicuous brown colour, both of which features afford fairly reliable means of deciding whether or not this tissue has been actively secreting. 
In view of this evidence it is difficult to avoid the conclusion that it is the amylase secreted by the aleurone layer, and this enzyme alone, which in experiments with endosperms produces corrosion of the mature starch grains stored in the amyliferous cells.

The suggestion which has been made that other substances or bodies derived from the aleurone layer, not of an enzymatic nature, are capable of transforming the amylase resident in and augmented by the inner endosperm into an enzyme endowed with the attributes and properties of the 'secretion' amylase elaborated by the living scutellar epithelium and aleurone layer, can hardly be regarded with favour ; for under the conditions of experiment described above, death of the aleurone layer does not preclude the free diffusion of such substances as those suggested into the subjacent amyliferous tissue, and if these were capable of effecting any such transformation as that suggested, we should expect to find as one of the first indications some evidence of starch-erosion. Since this is not the case, there remains only to reiterate the statement, that it is the amylase secreted by the aleurone layer which produces the phenomenon observed, and dominates endospermic depletion (as exhibited by the isolated endosperm), and to repeat that the processes which occur in the isolated inner endosperm are distinctly and for the most part of an auto-digestive nature, such as those which a dead enzyme-containing tissue may be capable of inducing in its contents.

\section{Cultures of endosperms and inner endosperms on moist calcium sulphate.}

Similarly constituted experiments were carried out with endosperms and inner endosperms on moist calcium sulphate, the antiseptic now being nitrobenzene, and the temperature of these 'culture' experiments being $24^{\circ} \mathrm{C}$.

The results are shown in Table XXIV below, and the conclusions to be derived from them are in no way opposed to those furnished by the gelatine cultures.

There is an entire absence of eroded starch grains in Experiment 3 (a phenomenon which is invariably in evidence when the aleurone-layer functions are not interfered with), and the total reducing sugars found in the medium and objects belong to the same order of magnitude as in Experiments I and 2. 


\section{TABLE XXIV.}

\section{CULTURES OF ENDOSPERMS AND INNER ENDOSPERMS ON MOIST} Calcium Sulphate saturated with Nitrobenzene.

\begin{tabular}{|c|c|c|c|c|}
\hline Exp. & Objects. & $\begin{array}{l}\text { Reducing sugars per } \\
20 \text { objects in :- } \\
\text { Medium. Objects. } \\
\text { (equivalent to }\end{array}$ & $\begin{array}{l}\text { Amylase per } 20 \text { objects } \\
\text { per hour in:- } \\
\text { Objects. } \\
\text { ng. of Cu.) }\end{array}$ & $\begin{array}{l}\text { Weight of } 5 \text { objects } \\
\text { at termination of } \\
\text { culture experiment. }\end{array}$ \\
\hline I. & 5 inner endosperms & 29 & - & 135 \\
\hline 2 & & 73 & I68 & 175 \\
\hline & 5 endosperms & 95 & - & 212 \\
\hline
\end{tabular}

Experiment I. Inner endosperms prepared from air-dried seeds by filing off aleurone layer; objects steeped successively in ( $r$ ) absolute alcohol, (2) water. 48 hours in each reagent.

Experiment 2. Intact seeds steeped in (I) absolute alcohol, (2) water. 48 hours in each reagent, and aleurone layer then removed with razor.

Comparison of the results of Experiments I and 2, Table XXIV with Experiment 3, Table XX, shows that amylohydrolytic action proceeds to practically the same extent in anaesthetized inner endosperms as in those where no anaesthetic agent is employed, i. e. the inner endosperm behaves like a lifeless tissue.

Comparison of the results of Experiment 3, Table XXIV with Experiments I and 2, Table XX, shows a very striking difference; not only is the total amount of the reducing sugars significantly lower, but the weight of tissue remaining at the termination of the culture experiment is only feebly reduced.

The results, again, are obviously due to suppression of the secretory function of the living aleurone layer, and they afford strong confirmatory evidence of the results already derived from the more direct method of investigating this function described in Section IV, Table X.

\section{Starch-Liquefying and Saccharifying Properties of (I)}

Embryo AND Aleurone-layer Secretions, (2) Extracts of ENDOSPERMS AND INNER ENDOSPERMS.

The methods of culture employed permit of the separate collection and investigation of the secretions of the embryos and aleurone layer comparatively free from substances likely to exert any very marked influence on their intrinsic properties. Similar advantages accrue in the case of endosperms and inner endosperms cultivated separately on moist calcium sulphate substrata. In this latter case the examination amounts to a comparison of the behaviour, on the one hand (endosperms), of a mixture of residual amylase and that derived from the aleurone layer; on the other (inner endosperms), to the residual amylase reinforced by that 'liberated' during culture.

Since it was inconvenient and impracticable to prepare the secretions of the embryo and aleurone layer as required, the following method was devised :- 
A number of cultures of these objects on $0.55 \%$ asparagin-mineral salt medium were prepared in advance, and when ready, after ascertaining that they were perfectly sterile, the objects were removed, and the amylasecontaining medium was withdrawn by means of previously sterilized pipettes which were filled as completely as possible and at once sealed off.

Thus conserved out of free contact with air and protected from the light, the enzyme retains its primitive activity for a considerable time.

Endosperms and inner endosperms, at the termination of the culture period on moist calcium sulphate, were first desiccated at $30^{\circ} \mathrm{C}$. for twentyfour hours, and were then transferred to an ordinary desiccator containing $\mathrm{H}_{2} \mathrm{SO}_{4}$ as desiccating agent.

Determinations of starch-liquefying and saccharifying power of embryo and aleurone-layer secretions, and of aqueous extracts of endosperms and inner endosperms after cultivation on moist calcium sulphate.

After a number of preliminary trials of methods of Lintner Sollied ${ }^{1}$ and Pollak, ${ }^{2}$ the latter method as modified by Chraszcz $^{3}$ was adopted throughout the course of these experiments.

The modification introduced by Chraszcz merely consists in the employment of potato in place of arrow-root starch, and substituting other temperatures for that indicated by Pollak, viz. $37 \cdot 6^{\circ} \mathrm{C}$.

Briefly described the details of this method are as follows :-

Into each of a series of test tubes of uniform size and diameter Io c.c. of a $4 \%$ potato-starch suspension are pipetted, and the tubes and their contents are then rapidly placed in a boiling water-bath and their contents rapidly gelatinized at a temperature of $65^{\circ} \mathrm{C}$. They are then cooled to about $60^{\circ} \mathrm{C}$. and transferred to a thermostat the temperature of which is regulated at $55^{\circ} \mathrm{C}$. When the contents of the tubes have acquired this temperature a definite but gradually increasing volume of the amylasecontaining solution to be investigated is added successively to each tube.

Immediately after the addition of the enzyme solution the tube is closed with a rubber cork; it is then inverted and thoroughly shaken to ensure thorough mixing of its contents, and at once returned to the bath. Each succeeding tube is similarly manipulated, and after the lapse of a chosen time interval, of the same duration for each tube, they are successively removed and at once examined as follows :-

Two to three drops of strong alkali $(\mathrm{NaOH})$ solution are delivered from a pipette directly into the digestion liquid, and the manner in which they descend through the liquid is carefully noted. If the drops, during their descent, retain their spherical form, complete liquefaction has not taken place; if, on the other hand, the drops tend to lose their sphericity and

1 Zeitschr. f. das gesamte Brauwesen, xxxvi, I903, p. 329 .

2 Wochenschr. f. Brauerei, $x x, 1903, p .595$.

3 Pierozek, Wochenschr. f. Braterei, xxvii, 16, 1910, p. 186. 
become diffuse, then liquefaction is assumed to be either partial or complete. This point may be even more sharply ascertained by adding two to three drops of an indicator such as alizarin or phenol-phthalein, and again sharply inverting the tube. In those tubes in which liquefaction is incomplete the coloration produced by the indicator distributes itself in streaks, whereas in those in which complete liquefaction has taken place the distribution and intensity of the coloration is uniform throughout the mass. A second experiment with volumes of enzyme solution, chosen so as to include those comprehending and those lying on either side of the limits of incomplete and complete liquefaction indicated by the first experiment, enables the operator to hit off the volume of enzyme solution capable of producing complete liquefaction with a considerable degree of sharpness.

After the acquisition of sufficient preliminary experience the method is capable of affording quite reliable comparative results.

In the following tables are given the results of preliminary experiments with (I) secretions of the embryo and aleurone layers, and (2) aqueous extracts of endosperms, the secretions and extracts employed having equal saccharifying powers as ascertained by previously standardizing them by digestion with soluble starch.

\section{TABLE XXV.}

\section{Relative Starch-Liquefying and Saccharifying Powers of SECRETIONS AND EXTRACTS.}

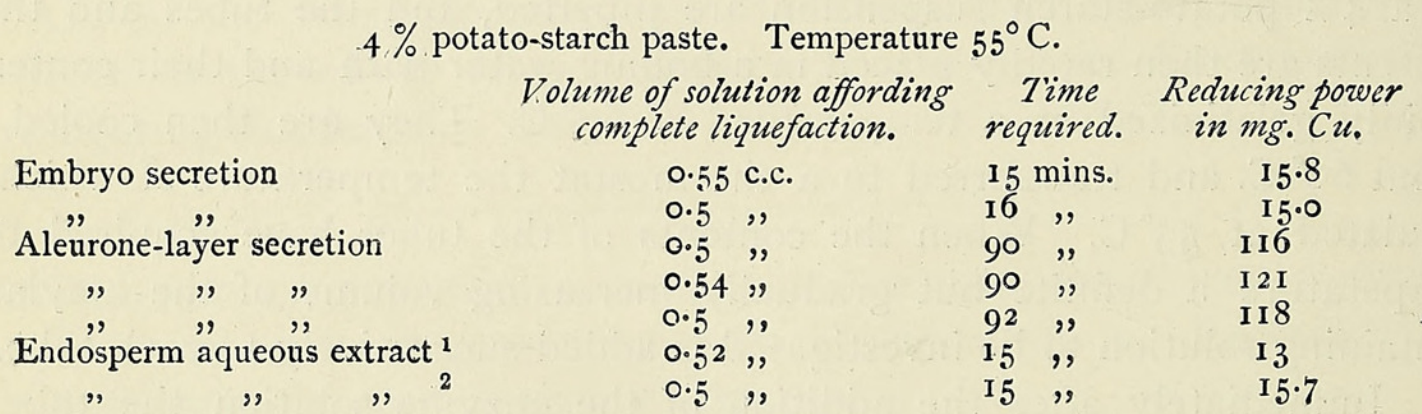

These results show approximately (the determination of liquefying power cannot be regarded as other than approximate, since the personal equation is invariably introduced) that when standardized solutions of embryo and aleurone-layer secretions prepared in the manner described, of equal saccharifying value with regard to soluble starch, are investigated as above the latter (aleurone-layer secretion) appears to possess feebler liquefying powers than that of embryo secretion but approximately the same saccharifying power.

Similarly standardized aqueous extracts of the endosperm, which are virtually extracts of the aleurone-layer secretion, are practically identical with those of embryo secretion.

\footnotetext{
${ }^{1}$ From culture of distal halves of endosperms.

${ }^{2}$ From culture of whole endosperms, steeped as such.
} 
The point to be considered in these comparative experiments is not so much the velocity of liquefaction as the point to which saccharification of starch paste may proceed.

Another series of experiments was then carried out on a larger scale as follows. Neither secretions nor extracts were standardized in this case, the object being to carry out prolonged digestions and then to determine the more important constants of these.

The following procedure was adopted in this and subsequent series:-

Two grammes of starch (potato) and 50 c.c. of water were placed in each of a series of 100 c.c. flasks, and the starch suspension, gelatinized at $65^{\circ} \mathrm{C}$. and afterwards cooled to about $55^{\circ} \mathrm{C}$., transferred to a thermostat retained at the latter temperature. Separate digestions were then carried out with embryo and aleurone-layer secretions and aqueous extracts of endosperms and inner endosperms at the various temperatures and times given in the table which follows. Toluene served as the antiseptic, and the flasks were securely corked during and at the termination of each experiment. Amylolytic action was arrested by plunging the flasks into a boiling water-bath for I 5-20 minutes. The contents of each, after cooling to $15^{\circ} \mathrm{C}$., were then brought to 100 c.c., filtered, and the different determinations recorded made in duplicate on the clear filtrate.

In each instance the values are adjusted by applying a correction for the copper-reducing substances found in the starch and added enzymecontaining solution.

\section{TABLE XXVI.}

\section{Conversion of $4 \%$ Potato Starch with Embryo and Aleurone-} LAYER Secretions AND Aqueous Extracts of Endosperms AND INNER ENDOSPERMS.

\begin{tabular}{|c|c|c|c|c|c|c|}
\hline Exp. & Source of amylase. & {$[a] D \cdot 3 \cdot 93$} & R. $3 \cdot 93$ & $\begin{array}{c}\text { Final }{ }^{3} \text { coloration } \\
\text { with iodine. }\end{array}$ & $\begin{array}{c}\text { Temperatur } \\
55^{\circ} \mathrm{C} \text {. } \\
\text { (Hours) }\end{array}$ & $\begin{array}{c}\text { of conversion } \\
30^{\circ} \mathrm{C} \text {. } \\
\text { (Hours) }\end{array}$ \\
\hline & Embryo secretion & $14^{8 \cdot 2^{\circ}}$ & 63.29 & No coloration & $\mathrm{I} \frac{\mathrm{I}}{2}$ & 14 \\
\hline & Aleurone-layer secretion & $145.5^{\circ}$ & $64 \cdot 5$ & Faintest violet & $1 \frac{1}{2}$ & $I_{4}$ \\
\hline & Endosperm extract 1 & $149 \cdot 2^{\circ}$ & 70.0 & No coloration & $\mathrm{I} \frac{1}{2}$ & 14 \\
\hline & 1 & $149 \cdot 8^{\circ}$ & 70.6 & " & $\mathrm{I} \frac{1}{2}$ & 14 \\
\hline & , $\quad, \quad 2$ & $140.0^{\circ}$ & $69 \cdot 5$ & " & 3 & - \\
\hline & Inner endosperm extract & $\mathrm{I} 55.9^{\circ}$ & $7 \cdot 66$ & Blue & 8 & 14. \\
\hline
\end{tabular}

The blue coloration (Experiment 6) persisted throughout the whole course of this experiment.

It is to be noted that the colour reaction given by the aleurone-layer secretion (Experiment 2) was of the faintest violet. The progress of liquefaction in Experiments 3, 4, and 5 was practically at the same rate, as judged by inspection of the limpidity and mobility of digestion liquid.

1 Culture of distal halves of endosperms, 7 days, calcium sulphate. Seeds steeped $4^{8}$ hours in absolute alcohol, 48 hours in water.

2 Endosperms of air-dried seeds steeped as in 1.

3 Colour reactions with iodine recorded in table noted at termination of digestion at $55^{\circ} \mathrm{C}$. 


\section{58 Stoward.-Amyloclastic Secretory Capacities of the}

There is a rough general agreement in constants for Experiments I-5, indicating that the stage to which conversion had finally advanced in each instance was practically of the same order. In particular the colour reactions in these experiments with iodine were identical.

On the contrary the results given by the inner endosperm extract (Experiment 6) notably differentiate the general character of the conversion in this case; not only are the constants of a different order of magnitude, but the reaction with iodine throughout the entire period of experiment was persistently blue.

The enzyme present was that of the inner endosperm-the residual amyloclastic enzyme of the ungerminated grain of Brown and Morristogether with a certain proportion of an enzyme of the same type resulting from the liberation of enzyme existent in this tissue which Ford and Guthrie refer to as 'latent' amylase.

It is to be understood that the author does not consider the 'blue' coloration stage as final in this experiment; the probable reason why the ultimate 'violet' stage was not attained must be ascribed to the relative proportions of aqueous inner-endosperm extract and starch paste employed.

Invariably in these culture experiments with inner endosperms on calcium sulphate, whether established with objects prepared from steeped intact seeds (the objection to which is the possible diffusion of enzyme from the embryo and aleurone layer, which we have seen may be regarded as of small moment when steeping operation is confined to time and temperature limits recorded in this paper) or whether inner endosperms are prepared from air-dried material and are then steeped, there is a continual draining away of the amylase pre-existent initially in the tissue and of the amylase which results from the liberation of 'occluded' or 'latent' enzyme, the net result of which is that as the culture experiment under these conditions is sufficiently prolonged this tissue eventually becomes denuded of its amylolytic enzyme content.

The calcium sulphate stratum undoubtedly contains this enzyme during the progress and at the termination of the experiment, but the difficulty of estimating its amount lies in the fact that experimental difficulties are met with; the distribution of enzymes in the semi-solid medium is not uniform, and hence equal division of the substratum by mechanical division into two identical halves is impracticable. Similarly in the extraction of the substratum with water it is impossible to eliminate completely the possible adsorption of enzyme by solid $\mathrm{CaSO}_{4}$. Finally, as already insisted, a far more accurate estimate of the relative depletive power of an amylolytic enzyme contained in or generated by a given tissue is gained by determining. the amounts of reducing sugars in the substratum than by comparing its relative amylase content.

In the former we measure the amount of a substance which is, 
a definite chemical individual, in the latter a body about which we know comparatively little either as regards its constitution or properties.

The object of the foregoing experiments has been to show that wherever the influence of the aleurone layer has been operative there is produced an enzyme which possesses properties which in all respects are comparable, if not identical with those of the enzyme secreted by the columnar epithelium.

The introduction of Experiment 6 in the series had for its object the demonstration of the fact that wherever the functions of the aleurone layer have been eliminated or rendered inoperative the enzyme present does not possess either the attributes of that of the embryo or aleurone-layer secretion.

The means of differentiation between the enzymes from these different sources hitherto relied upon were confined to observations (I) on the mode of attack on intact starch grains, (2) on the quantitative demonstration of the superior depletive activity possessed by the enzymes secreted by the embryo and aleurone layer, and now they are still further emphasized by direct experimental evidence afforded by starch-paste conversions.

The following experiments were carried out with inner endosperms which had been placed on calcium sulphate substrata for ten days. A digestion with soluble starch by the 'direct' method of digestion showed that the amount of 'free' amylase present was minimal, and it was therefore of interest to ascertain whether by the predigestion procedure with papain or neutral salt the 'latent' enzyme liberated by these methods would acquire any of the properties (as judged by their action on starch paste) of the more powerful amyloclastic enzymes derived from the embryo and aleurone layer.

\section{TABLE XXVII.}

Starch Conversions With InNer Endosperms. $4 \%$ Starch PASTE. 50 C.C.

I. to inner endosperms pre. c. c. $0.5 \%$ papain at $30^{\circ} \mathrm{C}$.

2. Io inner endosperms predigested 40 hrs. with 25 c.c. $0.5 \%$ papain at $30^{\circ} \mathrm{C}$.

3. ro inner endosperms pre. digested with $5 \% \mathrm{KCl}$. 40 hours at $30^{\circ} \mathrm{C}$.

4. Io inner endosperms extract. ed 4 hours with 25 c.c. water at $30^{\circ} \mathrm{C}$.

5. Io inner endosperms finely ground and added directly to starch paste.

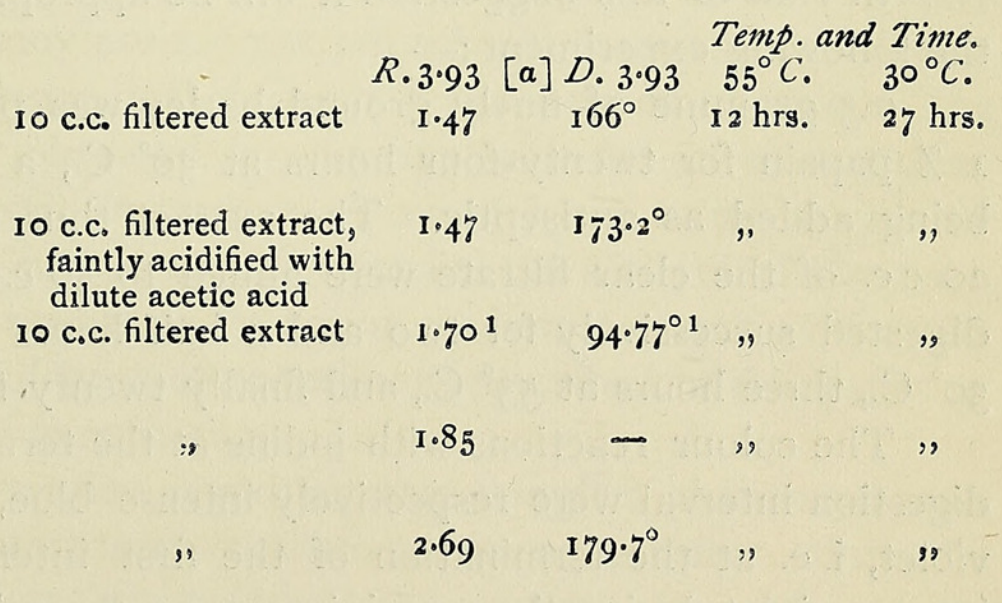

1 Values not adjusted for influence of neutral salt. 
Slow but complete liquefaction accompanied by the customary 'break' or separation of a flocculent material occurred in Experiments I, 2, 3, and 5, but in Experiment 4 these features were entirely absent.

The iodine reaction was persistently blue throughout the course of the conversion. The method of predigestion failed to induce in the 'latent' enzyme the acquisition of those specific properties which differentiate 'secretion' amylase as a more or less distinct type of amylolytic enzyme.

These starch-conversion experiments were not regarded as satisfactorily settling this point, and similarly conducted experiments, with the exception that the concentration of starch was lower, were undertaken in order to ensure the action of residual amylase attaining those final stages which are marked by the appearance of a persistent violet coloration with iodine.

It has been definitely shown by Baker ${ }^{1}$ that in starch-paste conversions with the amylase of ungerminated barley the reaction never goes beyond the violet coloration, and further that the conversion products formed by its action on starch paste are different from those formed by malt amylase in otherwise similarly conducted conversions.

The view has been recently advanced by Ling $^{2}$ that digestive transformations of storage contents and organized structures (cell walls and cytoplasmic contents) of the inner endosperm are conditioned solely by enzymes residual in this tissue. In particular does this refer to digestive changes in the starch-storage reserves. The amylase, both 'free' and 'occluded' or 'latent', resident in the inner endosperm-according to Ling - undergoes transformation into that of malted corn, i. e. the amylase of the resting grain (as the germinative process progresses) virtually acquires the properties of malt amylase, and it is further assumed that the process of transformation in the germinating seed under malting conditions is closely paralleled by that which takes place when resting barley is subjected to auto- or papain-digestion.

In view of this suggestion it will be appropriate in this section to note the following experiment :-

0.5 gramme of finely ground barley was predigested with 2.5 c.c. of I \% papain for twenty-four hours at $30^{\circ} \mathrm{C}$, a small quantity of toluene being added as antiseptic. The extract thus prepared was filtered and 20 c.c. of the clear filtrate were added to 50 c.c. of $4 \%$ starch paste and digested successively for two and a half hours at $55^{\circ} \mathrm{C}$., twenty hours at $30^{\circ} \mathrm{C}$., three hours at $55^{\circ} \mathrm{C}$, and finally twenty-four hours at $30^{\circ} \mathrm{C}$.

The colour reactions with iodine at the termination of each successive digestion interval were respectively intense blue, intense violet, less intense violet, i. e. at the termination of the first interval blue, and a persistent intense violet during the remaining ones; the colour test being carried out

1 Baker: Journ. Chem. Soc., Ixxxi, 1902, p. II 77 .

2 Ling: Journ. Inst. Brewing, xiv, I908. 
under identical conditions by removing two drops of the digestion mixture, diluting it by the addition of 5 c.c. of distilled water, and then adding two drops of iodine solution. These results definitely show that the amylase of ungerminated barley, even after predigestion with papain and subsequent lengthy digestion with starch paste, is incapable of advancing the conversion beyond that stage which gives a violet coloration with iodine. That is to say, the experiments so far considered afford presumptive evidence of the fact that the amylase of ungerminated grain does not undergo transformation into or acquire one of the most specific properties ascribed to the amylase found in the malted corn, viz. action on starch paste to the no coloration phase with iodine.

After arrest of amylolytic action by boiling, cooling, and diluting to I00 c.c. and then filtering, the determinations made on the clear filtrate yielded the following constants: R. $3 \cdot 93,58 \cdot 29$; [ $\alpha]$ D. $3.93,137 \cdot 2^{\circ}-$ values which no doubt arise as result of series of direct and reversionary actions.

The experimental evidence so far adduced shows that the amylase demonstrable in inner endosperms cultivated on calcium sulphate is differentiated from that contributed by the embryo and aleurone layer by the inferiority of its capacity to attack barley starch in the condition in which it exists in the amyliferous cells, by its mode of attack on starch grains, and further by its incapacity to carry the conversion of starch paste beyond the violet coloration phase, as well as by its inferior starchliquefying power.

It remains to add that the relatively large share attributed to the residual amylase in the digestion of the starch reserves of the inner endosperm during germination of the grain, as suggested in the more recent contributions to the subject, has been chiefly due to a tendency to confuse enzyme augmentation with enzyme activity and to regard the former phenomenon as an index of the latter. It has been frequently shown in the present inquiry that, although the inner endosperm is undoubtedly capable of augmenting its amylase content, yet this phenomenon is unaccompanied by any marked increase in the digestion of its starch reserves. The question has been further obscured by the apparent failure to recognize that the activity of amylolytic enzyme as measured by its action on soluble starch or starch paste does not necessarily parallel the activity of the same enzyme as measured by progress of its action on barley starch as it exists in situ either under the conditions of experiment described in this paper or under normal conditions of germination.

If we are to gain information regarding the complex phenomena met with in the germinative processes we must as far as possible study the mode of action of the enzymes which induce the changes observed not only in vitro but also in situ. 


\section{The Influence of Various Carbohydrates on the Secre- tion of Amylase by the Embryo and Aleurone Layer.}

The relative nutrient value to the embryo of certain carbohydrates was investigated by Brown and Morris (loc. cit., p. 483). As a source of readily assimilable carbon they found cane sugar to have the highest value of any of the various sugars examined. The important and interesting fact was also elicited that this carbohydrate inhibits the amyloclastic secretionary function of the columnar epithelial cells.

When, for example, cane sugar was included in the starch-gelatine culture medium used by these authors, upon which embryos alone were placed, or when embryos with the proximal halves of their endosperms attached were planted in loosely packed glass wool saturated with $3.5 \%$ cane sugar solution, no obvious signs of disintegration of starch granules were evident. This phenomenon, they state, is not due to inactivation of the secreted amylase (diastase) by the sugar present, but to the fact that "under these particular conditions the epithelial cells of the scutellum do not secrete any amylo-hydrolytic enzyme'. The secretion of active amylase by the columnar epithelium, they conclude, is to be regarded to some extent as a starvation phenomenon. ${ }^{1}$

The observations of Brown and Morris regarding the selective exercise by the embryo of its secretory functions is probably a widespread phenomenon. The secretion of various enzymes, more especially amylase, by different Bacteria and Fungi, as shown by the researches of Wortmann, ${ }^{2}$ Duclaux, ${ }^{3}$ Busgen, ${ }^{4}$ Fermi, ${ }^{5}$ Pfeffer, ${ }^{6}$ Katz, ${ }^{7}$ and Saito,${ }^{8}$ is influenced by the composition and constitution of the nutrient or experimental substrate.

In view of the important aspect of the regulative control which the embryo exercises over the secretory functions of the scutellum a number of culture experiments were carried out with sterilized embryos on media (liquid and semi-solid) containing either cane sugar, invert sugar, or dextrose, with the express object of studying the influence which each of

1 Quite recently Wohl and Glimm (Biochem. Zeitschr., xxvii, 1910, pp. 349-75), in an investigation of the extent to which the saccharification of starch paste by amylase is inhibited by addition of varions sugars, find that cane sugar in $20 \%$ concentration does not produce any inhibition.

The above statement of Brown and Morris is, therefore, well founded; the epithelial cells under the conditions cited and under my own experimental conditions do not exercise their secretory functions.

${ }^{2}$ Wortmann: Botan. Zeitung, 1890, p. 581 ; Zeitschr. f. physiol. Chem., vi, 1882, pp. 287-329.

3 Duclaux : Chimie biologique, pp. 193,195 , and 210.

4 Busgen : Ber. d. Deutsch. Botan. Gesellsch., Bd. cxi.

5 Fermi : Centralbl. f. Bakt. u. Parasitenkunde, x, pp. 40I-8.

6 Pfeffer: Pflanzenphysiologie, Bd. i, 1897, pp. $3^{61}$, 506.

7 Katz: Jahrb. f. wiss. Botanik, xxi, 1898, pp. 599-618.

${ }^{8}$ Saito: Wochenschr. f. Eranerei, xxvii, 16, I910, p. I8I. 
these carbohydrates exercises on the phenomenon of regulative secretion by the isolated embryo.

In the following table examples are given of the regulative control the embryo exercises over the amyloclastic secretory function of the columnar epithelium :-

\section{TABLE XXVIII.}

\section{Influence of Cane and Invert Sugar on the Amyloclastic SECRETORY FunCtion OF THE EMBRyo.}

African barley. Seeds steeped in $10 \% \mathrm{CuSO}_{4}{ }^{1} 24$ hours, water 24 hours.

\begin{tabular}{|c|c|c|c|c|}
\hline Exp. & Culture medium. & $\begin{array}{c}\text { Duration of } \\
\text { cultur. }\end{array}$ & $\begin{array}{l}\text { Digestion } \\
\text { period. }\end{array}$ & $\begin{array}{l}\text { Amylase per } 20 \text { objects } \\
\text { per hour in medium } \\
\text { (equivalent to mg. Cu). }\end{array}$ \\
\hline I. & M.S. $+5 \%$ cane sugar & 8 days & 20 hours & $2 \cdot 0$ \\
\hline & $0.55 \%$ asparagin-M.S. $+5 \%$ cane sugar & & $2 \frac{1}{2} \quad$, & 0.00 \\
\hline 3 . & $0.55 \%$ asparagin-M.S. $+5 \%$ invert sugar & 7, & I hour & I $56 \cdot 7$ \\
\hline
\end{tabular}

There can be little doubt that in presence of cane sugar, in close agreement with the observations of Brown and Morris, the embryo restricts its amyloclastic secretory powers in a very marked degree. Invert sugar, on the contrary, as Experiment 3 shows, is almost without influence on the exercise of this function of the embryo, amyloclastic enzyme being secreted just as rapidly and freely as when it is not included in the culture medium. The embryo, as we shall see, when the medium contains dextrose, exercises its regulative powers and reins in the activity of the secretory epithelial cells, but not to the same extent as in the case of cane sugar.

As the cultural experiments of Katz (loc. cit.) indicate, the secretory functions of Penicilium glaucum, Aspergillus niger, and Bacillus megatherium are influenced by different carbohydrates in varying degree, depending on the particular carbohydrate and its concentration.

The foregoing experiments and those which follow similarly demonstrate that the barley embryo adjusts or regulates its secretory powers; these vary with the carbohydrate employed, and, no doubt, with its concentration, although this aspect of the subject has not been experimentally investigated.

The data in Table XXIX below relate to cultures of embryos from seeds (Chilian barley) steeped successively in absolute alcohol and water under the customary conditions.

Two contemporaneous cultures of forty embryos each, the one on $5 \%$ gelatine-mineral salts (control), the other on the same kind of medium

1 The steeping of material in this reagent does not seriously interfere with the subsequent growth and secretory activity of the embryo (see Section XIII : Inadmissibility of $\mathrm{CuSO}_{4}$ as Sterilizing Agent), 
with the addition of cane sugar ( 5 grms. per 100 c.c. of medium), were continued for thirty-three days; the objects were then dissected into scutella, rootlets, and plumules, and the dissected material (after desiccation) and media were then investigated separately.

\section{TABLE XXIX.}

\section{Culture of Embryos on Gelatine Medium with and without CANE Sugar.}

\section{Exp. Culture medium.}

I. Gelatine-M.S. $+5 \%$ cane sugar

2. Gelatine-M.S. alone (control)

Amylase per 20 objects per hour in
medium, scutella, rootlets and plumules
(equivalent to $\mathrm{mg}$. Cu).
$\begin{array}{ccc}3.0 & 0.00 & 30 \\ 4.0 & 37.0 & \text { I I }\end{array}$

Throughout this long period of culture the embryos in Experiment I apparently did not secrete any amylase; practically none was found in either scutella or medium. The comparatively small amounts found in the control (Experiment 2) are no doubt due to partial destruction of amylase in the culture medium, owing to the unsuitable conditions which the medium offers for its conservation. External factors, atmospheric oxygen and light (although in all these experiments the cultures were shielded from the light as far as possible), also probably conspire to enfeeble and destroy the secreted enzyme

The embryo derives little or no nutriment from the gelatine. Throughout the many series of experiments in which gelatine media have been employed, no single instance of liquefaction by either the embryo or aleurone layer has been observed. The seedling under these conditions, in the absence of both available carbon and nitrogen, simply drains the scutellum of the valuable reserves stored initially in its tissues, reserves which we have assumed also serve in part for the manufacture of enzymes. The experiment is intended to demonstrate that when an ample supply of cane sugar is placed at the disposal of the embryo, it regulates and restricts its secretory activity even, as in the above case, when the culture period is markedly prolonged.

The results comprised in Tables XXX and XXXI refer to contemporaneous cultural experiments with embryos on the asparagin-mineral salt medium with and without dextrose. 


\section{TABLE XXX.}

\section{Influence of Dextrose on the Amyloclastic Secretory Function OF THE BARLEy EMBRyo.}

Chilian barley. Seeds steeped successively in (I) $\mathrm{CuSO}_{4} \mathrm{I0} \%$, (2) water; 24 hours in each reagent; 40 embryos each culture. Culture period, Io days.

\begin{tabular}{cc} 
Exp. & \multicolumn{1}{c}{ Medium. } \\
& \\
I. & $0.55 \%$ asparagin-M.S. (control) \\
2. & $0.55 \%$ asparagin-M.S. + I $\%$ dextrose \\
3. & I.I $\%$ asparagin-M.S. (control) \\
4. & I.I \% asparagin-M.S. + I \% dextrose
\end{tabular}

\begin{tabular}{|c|c|c|}
\hline \multicolumn{2}{|c|}{$\begin{array}{c}\text { Amylase per } 20 \text { embryos } \\
\text { per hour in:- }\end{array}$} & Weight of 40 \\
\hline $\begin{array}{l}\text { Medium. } \\
\text { (equivalent }\end{array}$ & $\begin{array}{l}\text { Objects. } \\
\text { to } \mathrm{mg} \text {. of } \mathrm{Cu} \text {.) }\end{array}$ & $\begin{array}{l}\text { embryos. }{ }^{1} \\
m g .\end{array}$ \\
\hline 219 & 22 & - \\
\hline $8 \mathrm{I}$ & I4 & \\
\hline 205 & 29 & 60 \\
\hline $9^{2}$ & I 4 & I 85 \\
\hline
\end{tabular}

Dextrose in the concentration employed in the foregoing experiments obviously diminishes the secretion of amylase by the embryo; not only, as Experiments 2 and 4 very clearly show, is the amount of enzyme found in the culture medium reduced, but in the objects themselves this also holds. There is, apparently, in these instances where either cane sugar or dextrose is available, no need for internal digestion, and hence the secretion of enzyme is absent or greatly diminished. The embryo, therefore, regulates its secretory mechanism largely according to the nature and constitution of the supply of external nutriment. ${ }^{2}$

Luxuriant growth of the embryo invariably occurs on both solid and liquid media with the addition of either of the carbohydrates mentioned. Comparison of the weights of the embryos (Experiments 3 and 4) affords typical examples of the increased assimilation and growth which take place in these circumstances.

This latter observation at one time suggested that possibly active secretion took place in these cells, but was wholly intracellular, the rapidly absorbed cane sugar undergoing transformation and condensation in the epithelial cell, and the starch thus formed being subsequently hydrolysed into readily diffusible sugar and translocated to the actively growing parts of the young plantlet.

The absorption of nutriment by the isolated embryo under the artificial cultural conditions described is extremely rapid, as shown by the turgid appearance presented by the scutellum. Unless assimilation keeps pace with this enhanced absorption, the osmotic forces within this tissue reach such a high value that the organ ruptures. This frequently occurs in the case of $Z e a$ (maize) seedlings, the scutellum being split right across, a deep

1 Desiccated 6 hours at $30^{\circ} \mathrm{C}$.

${ }^{2}$ Sections through the scutellum of embryos nourished with these carbohydrates singly show on treatment with iodine the presence of starch in quantity in the scutellar tissues. Similar microtomed fixed and stained sections, especially those prepared from embryos removed during the first 48 hours of culture on cane sugar media, show starch granules in the columnar epithelial cells. 
rift traversing it from apex to base. The above experimental results, however, show that inclusion of dextrose in the culture medium inhibits the secretion of amylase in the tissues of the plantlet, for, as the above results indicate, the amount of amyloclastic enzyme in the embryos themselves is distinctly lower than in the controls.

The following table furnishes data of physiological interest, the experiments, as already stated, being contemporaneous with those of Table XXX :

\section{TABLE XXXI.}

Cultures of Embryos on Asparagin-Mineral Salt Medium With Dextrose.

Details of preparation the same as given in Table XXX.

\begin{tabular}{|c|c|c|c|c|c|c|}
\hline Exp. & & $\begin{array}{l}\text { Nitrogen initially } \\
\text { present in culture } \\
\text { medium. }\end{array}$ & $\begin{array}{l}\text { Residual } \\
\text { sugar in } \\
\text { medium. }\end{array}$ & $\begin{array}{l}\text { Nitrogen as- } \\
\text { similated by } \\
\text { plantlets. }\end{array}$ & $\begin{array}{l}N \% \text { in dry } \\
\text { plantlets } \\
\text { after culture. }\end{array}$ & $\begin{array}{l}\text { Dry weight of } \\
40 \text { embryos. }\end{array}$ \\
\hline I. & $\begin{array}{l}0.55 \% \text { asparagin- } \\
\text { M.S. I \% dextrose }\end{array}$ & I $4 \mathrm{mg}$. & 0.00 & $\mathrm{I}_{4} .8 \mathrm{mg}$. & 10.05 & $147 \mathrm{mg}$. \\
\hline 2. & $\begin{array}{l}\text { I.I } \% \text { asparagin- } \\
\text { M.S. I } \% \text { dextrose }\end{array}$ & 28, & 0.00 & 20.5, & II 68 & 175 \\
\hline
\end{tabular}

The results furnish a rough idea of the manner in which assimilable nitrogen and carbon are removed from the culture medium. In Experiment I, for example, both the total available nitrogen and carbon were absorbed, and in Experiment 2 a small residue of nitrogen only remained. The possible protective function to the secreted amylase, which has been ascribed by the author to asparagin, if exercised in these experiments and those comprised in Section III, evidently does not cover a very lengthy period of time. The complete removal of dextrose from the culture medium in these experiments leaves the question open whether the employment of higher concentrations of this sugar would stimulate the embryo to exercise its secretory restrictive powers as fully as it does when cane sugar replaces dextrose.

The foregoing results show that cane sugar and dextrose distinctly influence the amyloclastic secretory activity of the epithelial cells of the scutellum ; the presence of the former leads to the almost complete cessation of extra-cellular secretion, while the latter very considerably diminishes this phenomenon. Invert sugar, on the contrary, appears to be quite inert, secretion occurring in its presence in the particular concentration used, equally and to practically the same extent as when it is not included in the culture medium.

Similarly conducted experiments were also carried out with dorsal fragments of aleurone layers prepared from seeds steeped in copper sulphate.

These are summarized in the table which follows. 
TABLE XXXII.

Influence of Cane and Invert Sugar on the Amyloclastic Secretory Activity of the Aleurone layer.

African barley. Seeds steeped in (I) $\mathrm{CuSO}_{4}{ }^{1} 10 \%, 24$ hours, (2) water; 24 hours.

\begin{tabular}{|c|c|c|c|}
\hline $\operatorname{Exp}$ & Medium. & Duration of culture. & $\begin{array}{l}\text { Amylase per } 20 \text { objects per } \\
\text { hour, equivalent to mg. } \\
\text { Cu in culture medium. }\end{array}$ \\
\hline & 0.55 asparagin-M.S. & 4 days & $3^{6} 5 \mathrm{mg}$. \\
\hline & 0.55 asparagin-M.S. $+5 \%$ cane sugar & $5 "$ & $2 \mathrm{I} 5$, \\
\hline 3. & 0.55 asparagin-M.S. $+5 \%$ invert sugar & $4, "$ & $200 "$, \\
\hline
\end{tabular}

Since the material used in these experiments was prepared under identical conditions, the results given above are comparable among themselves. Apparently these sugars exercise little or no influence on the secretion of amylase by the aleurone layer. It must not, however, be regarded as demonstrated that the cells of this tissue do not exercise that regulative control over the secretory function which they undoubtedly possess. The apparent indifference of the aleurone layer to changes in the nutrient substrate is due to the fact, as already insisted, that we are dealing with an isolated fragment of a tissue, and not with a complete highly organized organism. When in contact with its natural substratum, the inner endosperm, it is highly probable that, just as in the case of the epithelium of the scutellum, the aleurone layer regulates its secretory activities according to the special demands of the moment.

\section{Investigation of the Amylase Content of the Scutella of Barley Seedlings.}

In dealing with the amyloclastic secretory capacities of the embryo and aleurone layer (Sections III and IV) it has been suggested that the output of amylase by these objects as measured by the quantitative examination of the culture medium is probably inferior to that which obtains under natural conditions of germination.

It will be generally accepted that the embryo and aleurone layer function best when, as in the germinating seed, they are in close relationship with the inner endosperm. There is, as we have seen, more especially (because more easily demonstrable) in the case of the embryo (see Sections III and VIII), a marked tendency to modify the extent and character of the activity of secretory mechanism localized in its scutellar epithelium according to the composition of the substratum on which it is placed. The exercise of a similar regulative control by the aleurone-layer fragment is not so clearly shown, the reason as already suggested being largely

1 Special reference will be made to the influence the copper salt has on the secretory activity of the aleurone layer, see Section XIII, p. II8I. 
dependent on the fact that instead of a complete organism we are dealing with an isolated fragment of tissue which possibly, during the later phases of cultivation on an artificial substratum, lapses into a semi-pathological condition.

In order to gain some idea of the probable order of the secretory capacity of the embryo under ordinary germination conditions, the inquiry was restricted to the examination of the amyloclastic powers of the scutellum, for it will be obvious that if the examination were extended so as to comprise the plumule, radicle, and rootlets the data obtained would necessarily show but one feature, namely, that of progressive increase due to the formation of new tissue and the laying down in each new cell of a small amount of amylase for the internal economies of the newly-formed units. It is, therefore, the capacity of the scutellum, the cells of which do not undergo multiplication, ${ }^{1}$ which is of interest in the comparison of the relative secretory powers of the embryo on its natural nutrient medium and on artificial substrata.

The material for investigation was derived from seeds, which after the customary steeping in absolute alcohol and water were germinated at laboratory temperatures $\left(\mathrm{I} 5^{\circ}-\mathrm{I} 8^{\circ} \mathrm{C}\right.$.) for periods varying from 3 to 8 days.

The embryos after removal from the germinated seeds were dissected into scutella and radicles and plumules, dried for 4 -10 hours at $30^{\circ}$, and subsequently the scutella investigated for amylase as already described, the finely ground desiccated material being directly added and well mixed with the starch solution.

\section{TABLE XXXIII.}

Amylase Content of Scutella of Barley Seedlings at Various Stages of Germination.

$\begin{array}{cc}\begin{array}{c}\text { Duration of } \\ \text { germination. }\end{array} & \begin{array}{c}\text { Amylase per } 20 \text { objects }^{2} \text { per } \\ \text { hour in } m g . C u\end{array} \\ 3 \text { days } & 263 \\ & 223 \\ 4 \text { days } & 357 \\ 5 \text { days } & -58 \\ & 153 \\ 7 \text { days } & 158 \\ 8 \text { days } & 248 \\ & 59 \\ & 59 \\ 8 \text { days } & 69 \\ & 69 \\ & 84 \\ & 94\end{array}$

Weight of $\mathrm{I} 0$ radicles and plumules. mg.

\begin{tabular}{l}
- \\
46 \\
\hline 5 \\
52 \\
47 \\
78 \\
70 \\
119 \\
124 \\
94 \\
74 \\
-
\end{tabular}

1 Examination of extensive series of serial microtome sections of the scutella of embryos from seeds after 0-2I days' germination failed to reveal any evidence of cell division in any of its phases.

2 Io objects were used in each experimental and control digestion. 
The above results show on the one hand that the secretory capacity of the scutellum falls as germination proceeds, on the other, that the amount of amylase found in the scutellum during the period $0-4$ days ${ }^{1}$ is considerable, and if we assume, as we may reasonably do, that a very large proportion of this is destined for external use in the inner endosperm, then the amount of enzyme found in the culture media of embryos on artificial culture is far from over-estimated. The period $0-7$ days appears to represent the limits of great secretory activity; from the eighth day onward the level of amylase production falls considerably, and the functions of the scutellum are in all probability during this period principally absorptive.

Beyond the period $0-4$ days the cytological changes are more difficult to follow, although distinct nuclear changes are very evident, showing, as do the data in the foregoing table, that the cells are actively functioning.

In short, the evidence here adduced relative to the amyloclastic capacity of the scutellum indicates that the capacity of the embryo is much superior when attached to its natural endosperm than when cultivated even on the most suitable of the artificial media so far essayed. A similar conclusion with regard to the capacity of the aleurone layer may be suggested by a comparison of its amylase content under similarly defined conditions of comparison (Section XIV).

\section{The Secretion of Cytase by the Embryo and Aleurone} LAYER.

The existence of a cellulose-dissolving ferment in germinating barley was noted by Brown and Morris (loc. cit.), and they state that the disintegration and dissolution of the cell walls of the amyliferous cells which commence at the onset of and continue during the progress of germination are due to a specific enzyme, cytase.

The seat of the production of the enzyme, they state, is the columnar (absorptive) epithelium of the embryo; the later work of Brown and Escombe (loc. cit.) shows that the principal seat of elaboration of this cytoclastic enzyme during germination is probably the aleurone layer.

1 Cytological study of microtomed stained sections of the scutellum during the period 0-4 days affords evidence which in certain essentials is in no way opposed to the biochemical data given above. During the period o-4 days, the solubilization of the conspicuous 'aleurone' and other grains with which the cytoplasm is crowded initially proceeds most actively; commencing in the sub-epithelial tissue it progresses gradually to the deeper-lying portions of the scutellar tissue. Within the period mentioned the great mass of these grains are rendered soluble and disappear from view. There is undoubtedly some correlation between this disappearance of storage substance and the production of amylase. The period does not represent one of remarkable growth. These substances do not serve purely for purposes of general nutrition, but in all probability largely for the more important work with which the scutellum is occupied at this phase, viz. enzyme elaboration, which proceeds in the specialized epithelial layer. 


\section{I 70 Stoward.-Amyloclastic Secretory Capacities of the}

The specificity of the enzyme has been challenged by Grüss, who suggests that the manifestation of its activity is merely a function of ordinary 'diastase'.

The study of cellulose-dissolving enzymes has been exhaustively carried out by Newcombe, ${ }^{1}$ and the conclusion is arrived at that barleymalt extract contains a specific cytoclastic enzyme.

Apart from the question of endeavouring to ascertain whether cytase really represents a distinct enzyme it appeared desirable to ascertain whether, as asserted by Brown and his co-workers, the secretion of a cytoclastic enzyme is one of the several functions of the embryo and aleurone layer.

The preparation of sterilized experimental material appeared to afford exceptional opportunities of testing the cytoclastic secretory powers of these objects over prolonged periods of time and of thus giving them full facilities for the display of their presumed cytoclastic functions under conditions which absolutely precluded the possible interference of disturbing influences, such as micro-organisms, \&c.

After the customary series of orientation experiments the following method of experiment was adopted :- Embryos and fragments of aleurone layers were prepared from seeds sterilized by steeping them successively in alcohol and water under the usual conditions, and placed upon thin transverse sections taken from various parts of the endosperms of similarly sterilized seeds.

In each of a series of Petri dishes was placed a triangular glass tripod, and on it were laid several microscopical slides and on each of the latter three microscopical coverslips were placed; the dishes were finally sterilized by heating to $160^{\circ} \mathrm{C}$., and afterwards when sufficiently cooled 2-3 drops of $5 \%$ gelatine-mineral salt medium were delivered with a sterilized pipette and a single thin endosperm section embedded in each little mass of medium. Prior to the setting of the medium either an embryo or aleurone-layer fragment was laid on the section with its scutellar or inner surface respectively downwards and in close contact with the section. Similarly prepared miniature 'cultures' containing endospermic sections without the superposition of the objects mentioned served as controls. A small quantity of sterilized water was then run into the dish in order to prevent undue desiccation of the droplet of culture medium.

Under these conditions it was possible to carry out experiments of long duration and to examine the section without disarranging its component parts, a point of very considerable importance when, as we shall see in these experiments, often the cytoplasmic network alone remains.

The object of these experiments was not to examine the progress of 1 Ann. Bot., xiii, I899, p. 79. 
amylo- and cytoclastic action so much as to note what ultimately happens to the walls and to the starch storage contents of the amyliferous cells during periods ranging from $\mathrm{I}$ to 4 weeks.

Under the conditions described, the enzymes in play having. free access to the starch granules in those parts where the plane of section literally divided the endospermic cells into halves and thus exposed their starch contents, solution of starch invariably appeared to precede, in point of time, action on the cell walls ; the latter, however, were distinctly swollen at this juncture and difficult to stain with either Congo red or Bismarck brown.

The embryo and aleurone layer do not attack the material at their disposal at equal rates-the action of the former on both starch and cell walls being at all stages of the experiment earlier, the reason being, as already insisted in the discussion of various experiments with fragments of the aleurone layer, that an isolated non-growing ${ }^{1}$ fragment of secretory tissue does not, as anticipation would lead one to expect, comport itself in any way comparable with that manifested by an organism like the embryo.

At an early stage, 2-3 days, examination of the sections placed under embryos invariably shows that marked corrosion of starch granules characteristic of the action of the amylase which it secretes, and simultaneously the cell walls of the section acquire a swollen, hyaline appearance. Later, 4-7 days, the section may be practically depleted of its starch contents and the cell walls broken up into spindle-shaped fragments of varying size. A little later these are digested, and then, if care is taken not to disturb the section, after cautious warming of the gelatine and allowing it to reset the section is literally reduced to a diagrammatic representation of the cytoplasmic network of each cell divested of its original cell walls and inclusions. The parts of the diagram previously filled in by the cell walls are now clear spaces. Gentle flooding of the preparation. with Congo red or Bismarck brown, both of which admittedly stain cellulosic structures, and subsequent cautious removal of the excess of stain merely result in the staining and rendering more easily visible of the meagre cytoplasmic network; that portion of the section formerly occupied by the cell walls remains unstained, showing that the appearances described are not due to optical properties of any presumed residual matter. At a still later epoch, 7-I4 days or longer, the network disappears, portions undergoing disintegration presenting a beaded appearance, and the organized structure noted during the period immediately preceding this phase gradually disappears; the network is reduced to a structureless mass of débris.

Finally it is to be noted that the aleurone layer included in the section entirely resists disintegration.

1 Repeated examination of the microtomed stained section of the aleurone layer prepared from germinating seeds at various stages fails to reveal any distinct signs of nuclear or cell division. 
The evidence afforded by these experiments, positive in character and extremely well defined, leaves little doubt that the embryo secretes an active cellulose-dissolving enzyme.

When we turn to the control sections, these experiments being conducted contemporaneously and under identical conditions, the contrast is remarkable; absolutely no visible sign of change is demonstrable in them. In order to more closely examine the cell walls, many of the sections were divested of their starch by treatment with diluted saliva; microscopical examinations of these sections and similarly treated sections, for purposes of control, taken from endosperms of seeds which had been simply steeped, failed to show any evident sign of alteration, the two series presenting identical appearances.

These results show with reasonable clearness that the changes observed were induced by the embryo.

Similar series of changes to the foregoing are induced by the aleurone layer, but there is, as already pointed out, this important difference : they are more long drawn out, i. e. the action is slower. The important fact to be noted, already to some extent foreshadowed by the evidence afforded by the experiments described in Section IV $a$, is that, if the miniature 'culture' experiment is sufficiently prolonged (IO-2 I days), corrosion of starch granules identical in every recognizable respect with that induced by and hitherto attributed solely to the amylase secreted by the columnar epithelium takes place.

The type of starch erosion observed by Brown and Escombe (loc. cit., p. 13), which they designate ' sub-aleuronic', represents, so far as my observations go, one of the earlier phases of the phenomenon. During the final stages of the experiments ( $2 \mathrm{I}-28$ days or longer) the phenomenon becomes quite general. The cytohydrolysis produced by the aleurone-layer section presents during its various stages features which closely parallel those described for the embryo.

During the course of the work described in this section the idea frequently suggested itself that the dissolution and digestion of both cell walls and starch granules were induced not by the direct action of the cytoclastic enzymes secreted by the epithelial and aleurone-layer cells, but possibly indirectly by the action of substances other than secretions, i.e. substances, not enzymatic in nature, on the pre-existent enzymes in the tissues, which pass during the prolonged course of these experiments from these secretory tissues into the subjacent inner endosperm tissue, and possibly activate the pre-existent enzymes present in them.

The experimental evidence adduced in Section VI did not favour this suggestion. The control experiments in those just described were not regarded as quite conclusive, for the reason that no means had been taken to annihilate the enzymes pre-existent in the thin section of endosperm employed; it must, however, be admitted that the controls as thus con- 
stituted show that the isolated section of the endosperm was unable to induce autonomously in any degree the changes just described.

In order to test this important point, experiments similar to those described in mode of preparation and duration were instituted with embryos and aleurone-layer fragments, placed upon endosperm sections prepared from seeds which had been previously put in water at $90^{\circ} \mathrm{C}$. and retained at this temperature for half an hour. Many of these burst their integuments, and the starch contents of the sections selected showed distinct evidence of partial gelatinization. It is inferred that the preexistent enzymes of the ungerminated grain are largely localized, as Ford and Guthrie's investigations show, and my own confirm, in the peripheral portions of the endosperm. ${ }^{1}$

The results were in no way opposed to those recorded above; dissolution and digestion of the amyliferous cell walls and starch content proceeded to the same extent as in experiments with unboiled sections, but the processes were obviously retarded, possibly by either physical or chemical changes in the endospermic tissue or both, induced by the agency of heat. ${ }^{2}$

These experiments naturally raise the question of what constitutes a 'control'; strictly speaking, in the above experiments what is wanted is a section of an endosperm with its enzymes destroyed. Heating, if sufficiently prolonged, certainly accomplishes this, but the possibility of introducing new and unfavourable conditions is not precluded, and these may seriously inhibit the action of enzymes, such as amylase, cytase, \&c.

The possibility of finding some means whereby self-digestion of the inner endosperm may be accomplished without the aid of the active secretions of the embryo and aleurone layer is granted, but, so far at least, the suggestion rests on a basis which is purely presumptive. The suggestion of Ling that the pre-existent amylase of the resting grain during germination is transformed into the amylase of malt, although the possibilities of such a transformation are conceded, is unsupported by experimental evidence, and for the present at least belongs exclusively to the domain of theory.

It is of interest in this present section to refer to certain results yielded by earlier attempts to demonstrate the cytoclastic secretory powers of the embryo and aleurone layer.

A series of small Petri dishes, $4 \mathrm{~cm}$. in diameter, each containing the gelatine-mineral salt medium, similar to that employed in the 'miniature

1 Finely ground endospermic substance of barley, placed in dry test-tubes heated for half an hour in an ordinary Koch's steamer, annihilates effectively the pre-existent amylase of the ungerminated grain.

${ }^{2}$ Further light on this subject is afforded by the experimental evidence given in Section XII (Inactivation of Amylase). 
cultures ' described, to a depth of Io $\mathrm{mm}$., were prepared and transverse sections of unboiled endosperms were placed in these ; before the complete setting of the medium some of the sections sank to the bottom, others remained at the surface; on the latter were placed, on separate plates, embryos and fragments of aleurone layers.

Starch dissolution as usual occurred in the sections at the surface, and also finally (after 2-3 weeks) in those at the bottom of the medium, but little action was noticeable on the cell walls.

The experiments showed very clearly that amylase of secretion had gradually diffused throughout the medium. The comparatively small amount of action on the cell walls, in the light of the experimental results yielded by the miniature cultures, must be taken to mean that the cytase, owing to the immensely large volume of culture medium, was so greatly diluted that its action was rendered almost inappreciable.

In fine, the results recorded in the present section furnish supplementary evidence of the possession by the embryo and aleurone layer of both amylo- and cytoclastic secretory powers. It must be added, in view of the fact that disintegration and apparent digestion of the cytoplasm take place under the conditions of experiment described, that the possession of a proteolytic function is to be ascribed to the embryo and aleurone layer. They further support the view that the inner endosperm is incapable of inducing the depletion of its starch contents.

Reference has frequently been made, in dealing with cultures of endosperms, to the corrosion of starch grains, which is a constant feature in these experiments, and to the invariable absence of this feature in inner endosperms, under similar experimental conditions, the inference being that the amylase secreted by the aleurone layer attacks and erodes starch grains in a manner which it is impossible to differentiate from that induced by the amylase secreted by the columnar epithelium. In the present section direct evidence has been rendered available by the actual placing of aleuronelayer fragments on barley starch grains, and subsequently demonstrating the characteristic features and progress of the action. It has also been shown that when starch-paste conversions are carried out with the aleuronelayer secretion the constants obtained do not differ greatly from those furnished by similarly conducted conversions with embryo secretions, and in either case the conversion proceeds to the stage which no longer gives a coloration with iodine. These facts are regarded as evidence that the cells of the columnar epithelium and aleurone layer are, physiologically speaking, identical.

The phenomenon termed 'double fertilization' or 'triple fusion' has been known for a long time, and the possibility of its widespread occurrence has received general acceptance from the majority of botanists. This phenomenon, although it is claimed that it occurs in Zea (maize), has not, so 
far as the writer is aware, been demonstrated in the case of Hordeum (barley). The fact that the aleurone layer possesses similar physiological attributes to those of the columnar epithelium suggests that the endosperm of Hordeum may possibly represent an abortive or undifferentiated embryo, in which case the aleurone layer may on the evidence adduced be regarded as the analogue of the columnar epithelium.

\section{Xi. Influence of the Embryo on the Augmentation of \\ AMylase by THE INNER ENDOSPERM.}

There can be little doubt that, apart from its secretory functions, the embryo by the exercise of its absorptive function modifies the rate of augmentation of amylase in the inner endosperm. Removal of the products of amyloclastic activity is a primary essential if the gradual transformation of the starch reserves is to proceed without interruption. If, for example, the accumulation of starch transformation products exceeds certain limits, then there the progress of endospermic depletion may be markedly retarded.

It appeared to be of interest to study the possible influence the embryo may exercise on the capacity the inner endosperm possesses of augmenting its amylase content. With this object in view sterilized steeped seeds were completely divested of their aleurone layers, and plate cultures were then prepared of inner endosperms with their embryos attached. The objects were embedded in $5 \%$ gelatine-M.S. medium, and the cultures thus established continued for periods of four and six days. Media and objects were then separately investigated for amylase by the methods already described. table:-

The results of these experiments are summarized in the following

\section{TABLE XXXIV.}

\section{CUltures of INNER ENDOSPERMS With THEIR EMbryos}

\section{ATTACHED.}

Exp.

I. 5 embryos with inner endosperms attached

2. 5 embryos with inner endosperms attached
Culture Amylase per 20 objects per hour in :period. Medium. Inner endosperms. Scutella. 4 days 3 I 74 6 days $\quad 3055$
$95^{2}$

873
75

105

The results are of interest in showing that the augmentation of enzyme in the inner endoserm proceeds more rapidly under these conditions than in the isolated inner endosperm under similar conditions of cultivation.

The relatively larger total amounts of enzyme, however, are partly to be accounted for by the secretory activity of the embryo, and probably also by the more prompt removal of the products of amyloclastic activity, leading to the more rapid release of the residual 'latent' amylase of the inner endosperm.

The embryo in these circumstances probably secretes more actively than under the artificial conditions described in an earlier section of this 
paper. Unfortunately, if the experiment is continued beyond about four days, there is a decided tendency for the embryo to become detached from its inner endosperm, and this tends to limit the period of experiment.

The inner endosperms in these experiments were carefully examined for starch grains exhibiting signs of erosive action. Repeated examination of specimens of the endospermic starch grains taken from various parts of the inner endosperm fail to reveal any eroded starch grains except in that part of the inner endosperm with which the exterior surface of the scutellum is in close contact.

It is clear, therefore, as in experiments with isolated inner endosperms, so in these experiments, that there is an entire absence of the amylase resident in the amyliferous cells corroding the starch grains at its disposal, this mode of attack being, as already stated, confined to the amyloclastic secretions of the embryo and aleurone layer.

\section{XiI. The Inactivation of the Amylase of Ungerminated BARLEY.}

The suggestion has frequently been put forward that either the active secretions or substances other than secretions which pass by diffusion from the epithelial and aleurone-layer cells during the germination process may possibly exercise an activating influence on the amylase pre-existent in the inner endosperm either in the condition of 'free' or 'latent' enzyme.

It therefore appears desirable to subject the question to experimental inquiry, more for the purpose of ascertaining what would happen than with the hope of acquiring any very definite indications of the nature of the changes induced.

In the following essays the influence exercised by the embryo and aleurone-layer secretions on the amylase of resting barley has been made the subject of inquiry. The enzyme solutions used were derived from separate cultivations of embryos and aleurone layers on asparagin-mineral salt solution. The culture liquids containing the active amylase were removed aseptically with sterilized pipettes, which were at once sealed and afterwards conserved in the dark for $2-3$ months prior to their use.

\section{TABLE XXXV.}

\section{Influence of Embryo Secretion on the Amylase of Ungerminated Barley Substance.}

Digestion period, I hour at $30^{\circ} \mathrm{C}$. Starch solution containing $5^{8}$ grms. starch solids per Ioo c.c. of solution.

Exp.

I. 5 c.c. embryo secretion +30 c.c. starch solution

Amylase equiva-

5 c.c. water +30 cc. starch solution +0.2 grm. barley

. 5 c.c. embryo secretion +30 c.c. starch solution +0.2 grm. barley

4. 5 c.c. embryo secretion +30 c.c. starch solution +0.22 grm. barley (boiled)

5. 5 c.c. embryo secretion (boiled) +30 c.c. starch solution +0.2 grm. barley

lent to $\mathrm{mg}$. Cu.

208

343

556

I 59

3 IO 
The barley used in these experiments and those which follow was finely ground in a Seck mill and afterwards passed three times through a finely-meshed horsehair sieve in order to secure uniformity of sample. The bulk sample prepared as described was conserved during the progress of these and the experiments which follow in a desiccator over $\mathrm{H}_{2} \mathrm{SO}_{4}$ and carefully shielded from the light.

The values given in the above and following tables have been corrected by deducting the copper-reducing values of similarly conducted control digestions with boiled preparations of secretions and barley substance.

Experiments I and 2 give the separate amyloclastic powers of the embryo secretion and barley substance respectively. Experiment 3 shows clearly that the combined activities of the embryo secretion and barley substance roughly correspond to the sum of their separate values; each enzyme apparently retains its individuality and behaves as an independent unit. There is no evidence in this experiment of either activation or inactivation.

Where, as in Experiments 4 and 5, the influence of boiled barley substance or boiled embryo secretion on the embryo secretion and barley substance respectively is investigated, there is positive evidence of inactivation. The amyloclastic power of the embryo falls from $208 \mathrm{mg}$. to I $59 \mathrm{mg}$., while that of the barley substance decreases from $343 \mathrm{mg}$. to 3 IO mg., and the results so far considered negative distinctly the suggestion that activation of the amylase of the resting grain is produced by the amyloclastic secretion of the embryo.

Consideration of Experiments 3, 4, and 5 once more raises the question of what constitutes a control. If, for example, the sum of the values of Experiments 4 and 5, regarded for present purposes as of the nature of control experiments, viz. I $59+3^{10}=469 \mathrm{mg}$., be compared with the value furnished by Experiment 3, which equals $556 \mathrm{mg}$., then it would appear, in the absence of the results of Experiments I and 2, as though the amylase of secretion and barley amylase had mutually activated each other. Similar examples will be met with in the other series of experiments described in this section ; these will serve to emphasize the fact that experiments devised to show whether inactivation or activation of a given enzyme does or does not occur require special circumspection in the matter of design.

Below are given the results of similarly conducted experiments with the aleurone-layer secretion and barley amylase. 


\section{TABLE XXXVI.}

\section{Influence of Aleurone-layer Secretion on the Amylase OF UNGERMINATED BARLEY.}

Digestion period, I hour at $30^{\circ} \mathrm{C}$. Soluble starch solution containing 5 grms. starch solids per 100 c.c. of solution.

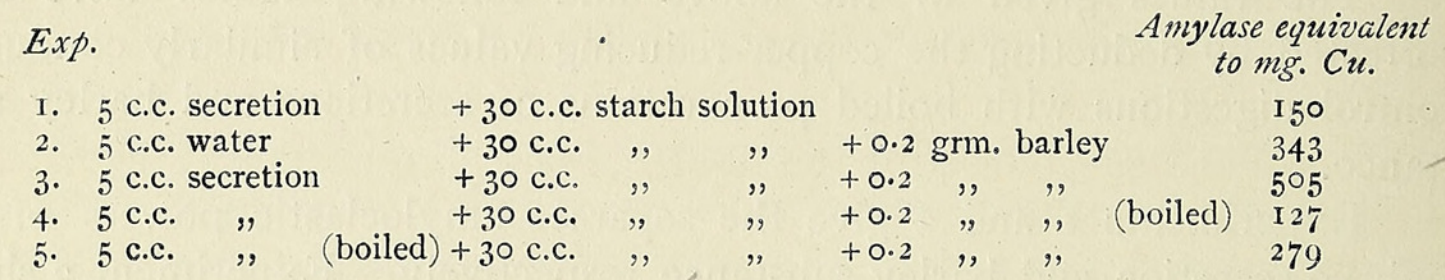

The results parallel those given in the preceding table in that they afford no evidence of activation of barley amylase either by the aleuronelayer secretion or by substances other than the amyloclastic enzyme contained by the secretion.

Experiments were then made to ascertain whether boiled barley substance or the same subjected to prolonged heating in the air-dry condition with and without free access of air exercises a retarding effect on the amylase of the resting grain.

The barley substance in these experiments was either (I) mingled with 5 c.c. water and boiled for ten minutes, or (2) the air-dried substance alone heated for three or more hours at $100^{\circ} \mathrm{C}$, or (3) the air-dried substance treated as in (2) and subsequently 5 c.c. water added and the mixture then boiled for ten minutes.

\section{TABLE XXXVII.}

\section{NFLUENCE OF BARLEy Substance on Amylase of Resting GRAIN.}

Digestion period, I hour at $30^{\circ} \mathrm{C}$. Soluble starch solution containing 6 grms. starch solids per Ioo c.c. of solution.

Exp.

Amylase equivalent

I. 0.2 grm. barley +25 c.c. starch solution +5 c.c. water

2. $0.2 ", "+25$ c.c. $", "+0.2$ grm. barley (boiled)

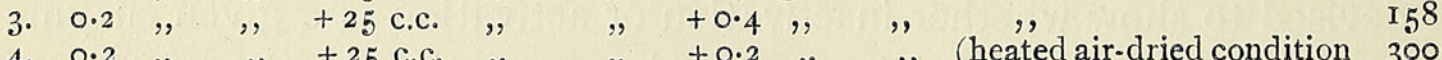

4. $0.2 ", \quad " \quad+25$ c.c. " $\quad+0.2 " \quad$ (heated air-dried condition 300

5. $0.2, \quad, \quad+25$ c.c. $, \quad, \quad+0.2, \quad, \quad$ (heated air-dried condition 285

3 hours at $100^{\circ} \mathrm{C}$., then boiled with 5 c.c. water for 10 minutes)

These experiments taken as a whole show that (I) boiled barley substance exercises a retarding influence on the amylase of the resting grain (compare Experiments I, 2, and 3); (2) barley substance which has been subjected to the treatment indicated in Experiments 4 and 5 apparently 
does not exercise any influence on the amylase present in the resting grain (compare Experiments I, 4, and 5).

At first it appeared to be probable that the inactivation produced by boiled barley substance in the above and preceding experiments might be due to adsorption of enzyme. This suggestion, however, is dispelled by the results of Experiments 4 and 5, and, moreover, Experiment 3, in which double the quantity of boiled barley substance was used, fails to lend support to such a surmise. The reaction of the boiled barley substance was approximately neutral to such indicators as alizarin and methyl-orange; it is therefore difficult to ascribe the results observed to change in the reaction of the digestion medium.

The interpretation of these results is a matter of difficulty; their general trend suggests the possible presence of an anti-enzyme, an anti-amylase, or of a phytotoxin, either of which might possibly be unmasked by boiling the finely-ground barley substance.

Further experiments were then instituted, the barley substance being subjected to one or other of the treatments set forth in the following table :-

Exp.

I. 0.2 grm. barley +25 c.c. $6 \%$ starch solution +5 c.c. water

2. $0.2,, \quad+25$ c.c.

3. $0.2, \quad, \quad, \quad+25$ c.c.$$
+
$$

$$
\text { s. }
$$

,"
,,
,

Amylase equivalent to $m g$ : $C u$.

316
321
190
200
205

These results do not differ materially from those given in the preceding table, with the exception of Experiments 3, 4, and 5, which show that more prolonged heating of barley substance in presence of water tends to reduce its retarding effect. As before, when barley substance is heated in the airdried condition (Experiment 2) the retarding influence which it previously exercised is entirely annulled.

Experiment 4 of the preceding and Experiment 2 of the above series, in which the air-dried substance was freely exposed to air and sealed respectively, seem to show that the inhibitory agent is not a volatile body.

The following series of experiments were essayed with the object of ascertaining whether the amylase which accumulates on predigestion with papain and is presumed to be due chiefly to the transformation of 'latent' into 'free' enzyme would in any way modify the character of the results previously obtained. 
I. 0.2 grm. barley +25 c.c. $6 \%$ soluble starch +5 c.c. water digested I hour at $30^{\circ} \mathrm{C}$. to $\mathrm{mg}$. Cu.

2. $\left(0.2\right.$ grm. barley +5 c.c. $0.5 \%$ papain solution, predigested 40 hours at $30^{\circ} \mathrm{C}$., then boiled) and afterwards 0.2 grm. barley +25 c.c. $6 \%$ soluble starch added and digestion continued for I hour at $30^{\circ} \mathrm{C}$.

3. ( 0.2 grm. barley +5 c.c. $0.5 \%$ papain solution, boiled) then predigested for 40 hours at $30^{\circ} \mathrm{C}$., after which 0.2 grm. barley $+25 \mathrm{cc}$. $6 \%$ soluble starch added and digestion continued for $\mathrm{I}$ hour at $30^{\circ} \mathrm{C}$.

4. 5 c.c. $0.5 \%$ papain solution, hoiled, and predigested for $4 \circ$ hours at $30^{\circ} \mathrm{C}$., after which $0.2 \mathrm{grm}$. barley added and digestion continued for I hour at $30^{\circ} \mathrm{C}$.

The foregoing results, however, do not modify the results obtained in previous experiments, the retarding effect of boiled barley substance being still in evidence (Experiments 2 and 3 ).

Finally, in view of the possible presence of substances (or bodies) capable of rendering the final reaction of the digestion mixture faintly alkaline or acid, the following digestions were carried out in presence of varying amounts of $\mathrm{KH}_{2} \mathrm{PO}_{4}$, the barley substance being boiled before and after the addition of the salt in Experiment 3 and Experiments 2, 4,5 respectively.

I. 0.2 grm. barley +25 c.c. $6 \%$ starch solution +5 c.c. water to $m g$. $\mathrm{Cu}$.

2. 5 c.c. $\mathrm{KH}_{2} \mathrm{PO}_{1}$ solution $+0.2 \mathrm{grm}$. barley, boiled +0.2 grm. barley +25 c.c. $6 \% 22 \mathrm{I}$ starch solution

3. ( 5 c.c. water +0.2 grm. barley, boiled) then phosphate added +0.2 grm. barley 2 I I +25 c.c. $6 \%$ starch solution

4. (5 c.c. $\mathrm{KH}_{2} \mathrm{PO}_{4}$ solution +0.2 grm. barley, boiled) +0.2 grm. barley +25 c.c. $6 \% \quad 200$ starch solution

5. (5 c.c. $\mathrm{KH}_{2} \mathrm{PO}_{4}$ solution $+0.2 \mathrm{grm}$. barley, boiled $)+0.2 \mathrm{grm}$. barley +25 c.c. $6 \% \quad 20 \mathrm{I}$ starch solution

The final percentages of phosphate in Experiments 2, 3, 4, 5 were $0.25 \%, 0.25 \%, 0.5 \%$, and I $\%$ respectively.

The inclusion of boiled barley substance in the digestion mixture again leads to retardation of the same order of magnitude as in the preceding series of experiments. The results obtained in presence of varying amounts of phosphate fail to lend support to the assumption that the final reaction of the digestion medium may have been contributory to the retardation effects observed in the earlier series of experiments. The possibility that the concentrations essayed were too high, it must be understood, is not excluded.

The experimental evidence brought forward in the present section tends on the whole to negative the view that the secretions of the embryo and aleurone layer in any way activate the amylase of the resting grain. The peculiar retardative influence exercised by boiled barley substance on barley amylase is a subject which calls for further investigation. 


\section{The Inadmissibility of Copper Sulphate as a StERILIZING AGENT.}

Copper sulphate, used in the concentration indicated and even in more dilute strengths, is unquestionably a most efficient reagent for effecting the sterilization of barley seeds, under the conditions described in this paper. It was repeatedly demonstrated, by means of several series of steeping experiments and subsequent bacteriological examination, that moulds were the only organisms which survived after the seeds had been subjected to twenty-four hours' immersion in $10 \%$ copper sulphate solution; the survival of these organisms, it is to be noted, occurred solely in a few instances, the various types of bacterial flora commonly present on the surfaces of cereal seeds being completely annihilated.

This reagent, however, offers certain disadvantages in an investigation like the present one, the chief of them being the difficulty of ensuring the complete removal of the last traces of the salt from the seeds by washing in water and the consequent risk of thereby introducing a disturbing factor in the subsequent culture and digestion experiments, the copper salt, even in minute traces, being extremely toxic towards amylase.

In the initial phases of the work embodied in this paper the culture experiments were confined to embryos. In view of the sensitiveness of amylase towards copper salts a series of parallel experiments were carried out with embryos steeped either in (1) $10 \%$ copper sulphate or (2) absolute alcohol. As the secretory capacities of the embryos in these experiments were of the same order of magnitude (such differences as were observed being attributable solely to the individualities of the organisms themselves), it was concluded that either the salt had been completely removed or its amount reduced to such small limits that it could no longer be regarded as a disturbing factor.

When, however, similar experiments were made with isolated aleurone layers considerable divergence in their secretory capacities were met with ; aleurone layers removed from seeds which had been steeped in the copper salt solution showed invariably a much lower capacity than aleurone layers from seeds which had been steeped successively in absolute alcohol and water. This divergence in the results was still more pronounced in endosperms and inner endosperms. In certain experiments with these objects, in spite of very thorough washing, the measure of their amyloclastic capacities fell from $\frac{1}{2}$ to $\frac{1}{10}$ of that yielded by similar objects in similarly conducted experiments prepared from seeds steeped in absolute alcohol.

To test the efficiency of attempts to wash out the copper salts, seeds were steeped in $10 \%$ copper sulphate for twenty-four hours, then washed with sterilized tap water (six re-washings being undertaken), and finally 


\section{82 Stoward.-Amyloclastic Secretory Capacities of the}

re-steeped in water for twenty-four hours. This steep water on concentration to small bulk acquired a faint but obvious blue colour, and confirmatory evidence of the presence of copper was obtained by testing the faintly acidified solution with potassium ferrocyanide.

It is evident, therefore, that in spite of what appeared to be very thorough washing, complete removal of the copper salt, or reduction of its amount to such small limits that its toxicity may be regarded as negligible, is not accomplished with any degree of certainty. It seems to be highly probable that copper sulphate interacts with a cellulosic or pectinous constituent in the seed coverings, forming a loose compound which possibly slowly dissociates in the culture medium. Although the salt probably exercises its toxic action on the amylase which diffuses from the objects into the culture medium during the progress of the culture experiment, the demonstration of such action is only rendered evident when the medium is digested with soluble starch.

The uncertainty associated with the use of copper sulphate as a steep reagent leads to its abandonment in favour of absolute alcohol. When airdried barley seeds are steeped in this reagent for 24-48 hours, abstraction of water and certain extractions from the seed coverings take place, but there is no evidence of penetration of the reagent into the interior of the seed, nor does the steeping of barley seeds in this reagent obviously impair their germinative capacities.

\section{Investigation of Material by the Auto- AND PAPAIN-Digestion Methods.}

The recent work of Ford and Guthrie ${ }^{1}$ shows that the amylolytic activity of ungerminated barley varies considerably according to the method of preparing the extract. Their results indicate that the extract of a given barley prepared by the auto- or papain-digestion methods described in their paper exhibits an increase of amylolytic activity over and beyond that yielded by the same barley when the method of preparation adopted is the customary or direct one usually employed. Thus, when a definite weight of ground barley substance is predigested under definite time and temperature conditions, either with plain distilled water, aqueous solutions of certain neutral inorganic salts, certain organic substances (notably amino acids), or with solutions of active (boiled) or passive (unboiled) papain, and the filtered extracts derived from these predigestions are digested with soluble starch under otherwise identical experimental conditions, they exhibit a much higher amylolytic power than do aqueous extracts prepared from the same barley by the customary method of short extraction. ${ }^{2}$

1 Journ. Inst. Brewing, I908, xiv, p. $6 \mathrm{r}$.

2 The authors state that these various substances do not directly stimulate amylolytic activity 
In ungerminated barley they assume that there exists a certain but variable quantity of amylase, which probably exists both in an insoluble and 'latent' condition. The notable augmentation of amylolytic activity (or more probably of amylolytic enzyme) which follows on predigestion, notably with active papain, they consider is due to the liberation and solubilization of this 'latent' enzyme, i. e. enzyme, it may be, occluded by or associated with a protein complex, which, especially in the presence of active papain, by virtue of its proteolytic function, is hydrolysed, and thus the enzyme assumed to be in the 'latent' condition undergoes liberation. Since passive papain leads to an augmentation of enzyme, and further, since the solution of this body possesses amphoteric properties, its functions are regarded as threefold; it (1) proteolyses and (2) solubilizes the latent enzyme, and on liberation and solubilization (3) protects it by ensuring the neutrality of the reaction medium. Aqueous predigestion, and particularly predigestion with aqueous solutions of certain neutral salts, also leads to augmentation of the enzyme, apparently in the main by enhancing its solubility.

Whatever may be the actual condition in which the great mass of the amylase of the resting grain exists, and the real nature of the mechanism operative in its release which ultimately leads to results similar to those described by Ford and Guthrie, there can be little doubt that when the amylolytic capacity of the ungerminated barley substance is investigated under conditions which closely parallel those employed by these authors, there ensues as a final result a very marked increase in the amount of amylase in the material as compared with that furnished by the ordinary method of determination. This notable increase in the amylase of the resting grain has naturally redirected attention to the subject of the causation of endospermic depletion. The questions which present themselves are, does not the residual amylase undergo similar augmentation during the progress of the germinative process, and does it not play a more important rôle in starch digestion than that attributed to it by Brown and Morris ? Prima facie considerations would naturally suggest that it does or may do so, but experimental evidence, at least for the time being, does not wholly support this hypothesis.

The pre-existent amylase of the resting grain was regarded, prior to the investigations of Ford and Guthrie, and justifiably so, as a small fraction only of that found in the inner endosperm of the seed after three to four days under conditions favourable to germination.

(Journ. Soc. Chem. Ind., 1904, xxiii, p. 414; and Journ. Chem. Soc., 1906, 1xxxix, p. 76); they consider that the increases of activity observed are not due to specific augmentation of the activity of the enzyme.

In short, the general conclusion to be gathered from their contribution is that the results recorded are due to the actual increase of amylolytic enzyme. 


\section{84 Stoward.-Amyloclastic Secretory Capacities of the}

Earlier researches, notably those of Rechyler, ${ }^{1}$ bear the suggestion of the possibility of autonomous enzyme augmentation by the inner endosperm, and associated with it is the idea that starch digestion must necessarily be the concomitant.

The positive experimental results adduced in the preceding sections amply confirm the first part of this suggestion. The isolated endosperm does possess this augmentative capacity; the phenomenon occurs under each set of experimental conditions exploited, and is quite independent of enzymatic or other possible influential substances which originate or are elaborated in either the aleurone layer or integuments.

In brief, under the conditions described the pre-existent amylase of the inner endosperm undergoes reinforcement, and the point is capable of experimental demonstration.

When we turn to similarly conducted experiments with the isolated endosperm, not only is augmentation of amylase of a superior order of magnitude a persistent feature, but accompanying it there is marked evidence, both microscopical and biochemical, of starch digestion and depletion, features which are conspicuous by their absence or marked reduction in magnitude in the experiments with the inner endosperm. Were it not for the independent proof of the secretory activity of the aleurone layer, it might be claimed that the auto-digestive phenomena presented by the isolated endosperms were entirely due to some indirect influence exercised by the former tissue, e.g. by the inward diffusion of salts or salt-like bodies or substances with amphoteric properties which respectively aid solubilization of the latent enzyme and afford the liberated enzyme adequate protection.

It is conceded that influences of the kind enumerated may, and probably do, play a rôle similar to that indicated in the general assemblage of processes which comprise the phenomena of starch digestion, but the view advanced here is that these influences are purely of an adjunctive type, and are overwhelmingly overshadowed by the rôle enacted by the enzyme which arises as the result of the operation of the secretory mechanism of the living aleurone-layer tissue. The evidence for this view lies in the very different results which attend the suppression of this secretory mechanism, and which are put forward in a later section.

The means there adopted, while they annihilate the glandular functions of the aleurone layer, do not preclude the diffusion of salt-like combination from this tissue into the inner endosperm. Why then, if digestion of the inner endosperm starch contents is independent of the secretions of the aleurone layer, does not the process, if it is conditioned by agents other than the actual secretions derived from this tissue, proceed in the same 
manner and to the same extent as when the glandular tissue exercises its full functional powers? Why does not the amylase of the resting grain, as suggested by Ling (1. c.), undergo transformation into the amylase of the malted grain and acquire the properties of the latter as we know them? Evidence will be adduced showing that the amylase derived from the aleurone layer possesses marked powers of attack on barley starch grains, the grains undergoing distinct and visible erosion. On the other hand, the amylase of the inner endosperm possesses but feeble powers of attack on the mature starch grains, and the erosive features are entirely absent. As we shall see when we come to deal with the experiments relating to papain-digestion, which lead apparently to the release of considerable quantities of the amylase resident in the inner endosperm, the fact, important as regards endospermic depletion, is brought to light that here also, in spite of the amount of diastase in action, the digestion of barley starch placed at its disposal under the condition of experiment is negligible. Still other important facts, relative to the nature of this enzyme and the condition in which it exists in the inner endosperm, will be advanced when we come to consider the results of the investigation of the structural parts of Tropaeolum, in which presumably the amylase present is wholly represented by the 'translocation' variety.

It appeared desirable, therefore, in view of the importance and stimulative interest possessed by the valuable contribution of Ford and Guthrie, to investigate, along lines closely parallel to those devised by them, the Chilian barley which has served in the majority of the experiments described, and further to extend the inquiry to the investigation of germinated material.

\section{Investigation of air-dried and steeped material.}

Materials derived from air-dried and steeped seeds were first investigated by the ordinary direct method of digestion with soluble starch, i. e. the finely-ground material was directly added to the starch solution at $30^{\circ} \mathrm{C}$., and the digestion continued at this temperature for a definite time-period, the object of these experiments being to ascertain whether the amylase content undergoes diminution after steeping, and also the influence exercised by the husks or certain of their constituents (organic and inorganic) on the result.

The results of the first series of experiments are given in the following table :- 


\section{TABLE XXXVIII.}

Material from Air-Dried SeEds : Amylase Content of Endosperms digested with and without Husks; of Husks and Aleurone Layers, Chilian Barley. Direct digestion method.

Exp.
1.
2.
3.
4.
5.
6.

$\begin{array}{lc}\text { Objects. } & \begin{array}{c}\text { Amylase per 20 objects per hour } \\ \text { (equivalent to } \mathrm{mg} . \mathrm{Cu}) .\end{array} \\ 5 \text { endosperms }+5 \text { husks } & \text { I378 } \\ 5 & \text { I } 280 \\ 5 \text { endosperms } & \text { I } 595 \\ 5 & \text { I6 I0 } \\ 5 \text { husks" } & 20 \\ 5 \text { aleurone layers } & 215 \\ 5 \text { objects in each experimental and control digestion. }\end{array}$

These results are extremely clear ; the order of magnitude of the amylase content of endosperms ${ }^{1}$ in Experiments $\mathrm{I}-4$ is the same, and in the barley in question the digestions with husks, instead of being higher, are lower than those without husks, a result which does not coincide with Ford and Guthrie's experiments. That certain barleys may exhibit this behaviour is possible. The husks themselves contain but little amylase, as is shown by the results of Experiment 5. The aleurone layers removed by filing off this tissue contain approximately $\frac{1}{6}-\frac{1}{7}$ of that found in the entire endosperm.

There appears to be a widespread idea that steeping may lead to very considerable reduction of the amylase content of a given barley. The fundamental correctness of this statement is no doubt perfectly sound, but there is considerable probability that the influence exercised by the manner of steeping and the conduct of the operation on different barleys is subject to very wide limits of variation. Ford and Guthrie (1.c., p. 67) suggest that the diminutions of amylolytic activity observed are due to the diffusion away of substances, both organic and inorganic, mainly from the husks during the operation.

The results summarized in the following table are derived from experiments instituted for the purpose of ascertaining in what degree the steeping conditions indicated influence the amyloclastic content of the endosperm.

1 In these and the experiments which follow, each experimental and control digestion was established with a definite number of objects (just as heretofore), and each object was divided longitudinally into its two component halves, one series of Io halves serving as the experimental and the other Io halves as the control digestion set. In this manner it was hoped that divergences due in the main to the individuality possessed by the objects under investigation might be in some measure reduced. 


\section{TABLE XXXIX.}

Alcohol and Alcohol Water Steeped Material: Amylase Content of Endosperms from $(a)$ Dehusked Seeds steeped in Absolute Alcohol for forty-eight hours, (b) Dehusked Seeds steeped successively in (I) Absolute Alcohol, (2) Water : forty-eight hours in each reagent.

Chilian barley. Direct digestion method.

\begin{tabular}{clll} 
Exp. & \multicolumn{4}{c}{ Objects. } \\
I. & 5 & endosperms $(a)$ \\
2. & 5 & $\#$ & $(a)$ \\
3. & 5 & $\#$ & $(b)$ \\
4. & 5 & $\#$ & $(b)$
\end{tabular}

Amylase per 20 objects per hour (equivalent to $\mathrm{mg}$. Cu).

I 435

1397

$\begin{array}{ll}\text { (b) } & \mathrm{I} 242 \\ \mathrm{II} 64\end{array}$

The values afforded by Experiments 3 and 4 certainly indicate the occurrence of reduction, but it is not enormous, and whether it is due in the major part to diminution of salt-like substances in the seed coats or testa (since the husks were removed before steeping in water in Experiments 3 and 4 ), or to actual existence of smaller amounts of amylase in the objects, remains an open question. In short, the barley employed is not one which exhibits the feature in a marked degree under the conditions of experiment selected. Moreover, the explanation of the phenomenon of reduction is probably much more complex, since the entry of water into the inner tissues of seed in all probability leads to a readjustment of the entire chemical, biochemical, and physical conditions of the complex reaction system which the endosperm, regarded as the sphere of action, represents.

\section{Investigation of air-dried and steeped material by the auto-digestion method.}

The amylase content of air-dried and steeped material was next investigated comparatively by the two methods of predigestion, (I) auto- and (2) papain-digestion, originated by Ford and Guthrie.

As usual, in place of using an aqueous or papain extract of the material these digestions were carried out in the presence of the finely-ground substance.

The uniform method adopted in these experiments, and also in those with material from germinated seed, to be described later, was that given below; the principal modifications being the reduction in the number of objects taken and increase in the volume and concentration of soluble starch solution used in each digestion experiment, changes necessitated by reason of the increase in the amylase content of certain of the structural parts of the seed under the new conditions of determination.

Each experimental and control predigestion and the subsequent digestion with soluble starch was carried out with 25 objects (intact seeds and structural parts); the seeds after removal from the steep or germinator being 
at once dissected or left intact as occasion demanded, and the dissected and non-dissected material subsequently dried for $4^{-10}$ hours at $30^{\circ} \mathrm{C}$. The mixture of desiccated material and sand was placed in small 50 c.c. conical previously steamed Jena flasks, and to each was added Io c.c. of either (I) plain distilled water (auto-digestion), or (2) solution of neutral salt (autodigestion), or (3) active or passive papain (papain-digestion), and, finally, a drop or two drops of an antiseptic, nitrobenzene or toluene. The flasks, securely corked, were then transferred to the thermostat at $30^{\circ} \mathrm{C}$., and there remained for 20 hours. After the contents of the flasks intended to serve as controls ${ }^{1}$ had been slightly but distinctly alkalinized by addition of $\mathrm{NaOH}$, the experimental and control digestions were commenced by the pipetting into each flask of 40 c.c. of soluble starch solution (equivalent to 50 c.c., containing $4 \mathrm{grms}$. of starch solids per 100 c.c. of solution), and continued for half an hour at $30^{\circ} \mathrm{C}$. The experimental digests were then arrested by the addition of alkali.

The table which follows summarizes the results of auto-digestion of the endosperms of air-dried seeds, and affords ample evidence of the capacity possessed by the endosperm under the conditions selected to augment its amylase content. Auto-digestion with husks, however, does not influence the result.

\section{TABLE XL.}

AjR-DRIEd Material: Amylase Content of Endosperms from Air-dried Seeds.

Chilian barley. Auto-digestion period, 20 hours. Antiseptic, nitrobenzene.

Exp. Objects.

I. 5 endosperms +5 husks

2. 5 " 5 ,

3. 5 + $\quad$ (without husks)

4. 5

5. $2 \cdot 5$
Amylase per 20 objects per hour (equivalent to $\mathrm{mg}$. Cu).

Experiments 1-4, 5 objects used in each experimental and control digestion. Experiment 5, 2.5

\section{Investigation of ungerminated barley substance by papain-digestion method.}

Material prepared from air-dried and steeped barley was subjected to predigestion with papain, under the conditions selected and described in the preceding section.

A series of preliminary trials, instituted for the purpose of gaining some idea of the order of magnitude of the change in the enzymatic capacity of

\footnotetext{
1 Arrest of control and experimental digestions was also carried out by boiling the digestion mixture in many instances.
} 
the structural parts of the seed induced by papain-digestions, was undertaken by the method of procedure already formulated. The trials showed definitely that a period of predigestion of the material with a 0.5 per cent. papain solution ${ }^{1}$ for 20 hours at $30^{\circ} \mathrm{C}$. was ample for the establishment of a condition of equilibrium.

The general characters presented by the results embodied in the tabular statements which follow show clearly that predigestion of material derived from air-dried and steeped seeds (endosperms, \&c.) with papain in the manner indicated invariably leads to a marked augmentation of its amylolytic activity or amylase content as compared with that observed when similarly prepared material is investigated by the direct digestion method employed elsewhere in this inquiry.

\section{TABLE XLI.}

\section{Air-DRied Dehusked Seeds: Amylase Content of Endosperms.}

Chilian barley. $0.5 \%$ papain, 20 hours. Antiseptic, nitrobenzene.

\begin{tabular}{|c|c|c|}
\hline Exp. & Objects. & $\begin{array}{c}\text { Amylase per } 20 \text { objects per hour } \\
\text { (equivalent to mg. Cu). }\end{array}$ \\
\hline I. & 2.5 endosperms & II 1050 \\
\hline & & 10800 \\
\hline 3 . & 2.5 & 8693 \\
\hline
\end{tabular}

The results of papain-digestion of inner endosperms and aleurone layers from air-dried seeds are shown in the following table :-

\section{TABLE XLII.}

AIR-DRIEd Dehusked SeEds: Amylase Content of Inner Endosperms and Aleurone Layers.

Chilian barley. $0.5 \%$ papain, 20 hours. Antiseptic, nitrobenzene.

\begin{tabular}{|c|c|c|}
\hline Exp. & Objects. & $\begin{array}{l}\text { Amylase per } 20 \text { objects per hour } \\
\text { (equivalent to mg. Cu). }\end{array}$ \\
\hline $\mathbf{r}$. & 2.5 inner endosperms & $64 I_{4}$ \\
\hline & 2.5, & 8103 \\
\hline & $2.5, "$, & 7752 \\
\hline & 5 aleurone-layer filings & $215^{2}$ \\
\hline
\end{tabular}

The aleurone-layer filings represent $19 \%$ of the total weight of 5 air-dried dehusked endosperms

Experimental inquiry was next directed to ascertain whether the con. centration ( 0.5 per cent.) of papain employed in experiments so far cited was the most favourable, the determination being confined to the examina-

1 The single specimen of papain used exclusively in these papain-digestions was procured from Messrs. Griffin, London. 
tion of seeds which had been steeped successively in absolute alcohol or water.

The papain solutions were prepared by weighing separately the requisite amounts of papain, and adding the necessary volumes of water to furnish the desired concentrations. The preparation of the papain extract was made, as customary in all these experiments described in this and other sections, by maintaining this solution at $30^{\circ} \mathrm{C}$. for $3-7$ hours in a tightly-corked flask, the risk of micro-organism development being eliminated by addition of one drop of nitrobenzene. To aid the progress of extraction the contents of the flasks were agitated at intervals; finally, the undissolved residue was filtered off, and each experimental and control predigestion carried out with 10 c.c. of the clear filtrate.

\section{TABLE XLIII.}

Amylase Content of Dehusked Seeds after steeping successively in (I) Absolute Alcohol, (2) Water ; 48 hours in EaCh REAGENT.

Chilian barley. Varying concentrations of papain, 20 hours. Antiseptic, nitrobenzene.

Exp. Objects. Concentration of papain.

\begin{tabular}{|c|c|c|}
\hline I. & $2 \cdot 5$ & eeds \\
\hline 2. & $2 \cdot 5$ & $n$ \\
\hline 3. & $2 \cdot 5$ & $"$ \\
\hline 4. & $\cdot 5$ & "I \\
\hline 5. & $2 \cdot 5$ & $"$ \\
\hline & $2 \cdot 5$ & , \\
\hline
\end{tabular}

$$
\begin{gathered}
0.5 \% \\
1.0 \% \\
1.5 \% \\
",
\end{gathered}
$$

The values furnished by this essay require but little comment; concentrations ranging between $0.5-\mathrm{I} \cdot 0 \%$ papain evidently do not greatly influence the order of magnitude of the results, the observed difference being regarded as being principally conditioned by the individuality of the objects examined. The employment of a higher concentration ( $\mathrm{I} \cdot 5 \%$ ), however, obviously does appear to be responsible for a diminution of the amylase content.

On the other hand, rough comparison of these results with those of Table XLI, p. II 89 (endosperms of air-dried seeds), appears to indicate that steeping has led to reduction of the amyloclastic enzyme content of the objects under notice. The interpretation of the influence of steeping is, however, by no means simple, and its further discussion may well be deferred until the results of further experiments, relating to the relative distribution of enzyme in the structural parts of the steeped seed, are adduced.

These are shown in the following table:- 


\section{TABLE XLIV.}

\section{Amylase Content of Endosperms, InNer Endosperms, ANd Aleurone layers for Dehusked Steeped Seeds.}

Chilian barley. Seeds steeped successively in (I) absolute alcohol, (2) water ; $4^{8}$ hours in each reagent. $0.5 \%$ papain, 20 hours. Antiseptic, nitrobenzene.

\begin{tabular}{|c|c|c|}
\hline Exp. & Objects. & $\begin{array}{l}\text { Amylase per } 20 \text { objects per hour } \\
\text { (equivalent to } \mathrm{mg} \text {. Cu). }\end{array}$ \\
\hline I. & 2.5 endosperms & 8070 \\
\hline 2. & $2 \cdot 5$ & $79^{8} 5$ \\
\hline 3. & 2.5 inner endosperms & 4888 \\
\hline 4. & $2.5 \quad$, & $554^{8}$ \\
\hline 5. & $2 \cdot 5$ aleurone layers & $34 I_{4}$ \\
\hline & $2 \cdot 5 \quad$ & $3^{I} 8 \mathrm{I}$ \\
\hline
\end{tabular}

There is an obvious reduction of amylase in the endosperm (compare Table XLI) and inner endosperm (compare Table XLII) and an increase in that of the aleurone layer. The reduction of enzyme apparently falls more heavily on that of the inner endosperm ; it does not follow, however, that some reduction does not occur in that of the aleurone layer, and if this be so, then the increase in the enzyme content of this tissue due to papaindigestion is actually greater than the value determined. The results observed may be conditioned to some extent by the mere separate digestion of these tissues (aleurone layer and inner endosperm), but the digestion of the endosperm (in which these structural parts are mixed) also shows reduction and therefore fails to lend support to this suggestion. A partial explanation may be suggested by the application of Ford and Guthrie's hypothesis, namely, the diffusion away, during steeping, of salts or salt-like substances and others, some of which, by virtue of their amphoteric properties, protect the released amylase, but bodies of the same type are, according to this hypothesis, contributed by papain.

The explanation, however, is more probably associated with the differences in the biological attributes of the two tissues.

There is good reason to believe that we are dealing with tissues which differ in this important respect. The aleurone layer is distinctly living; the inner endosperm, on the contrary, if it possesses vitality at all, can hardly be regarded without ample qualification as a living tissue. The inner endosperm, whether it forms an integral part of the seed or whether it is isolated, comports itself like a mass of dead tissue; the processes induced in it, viz. the augmentation of enzyme and the limited digestion changes, under cultural conditions and also by different digestion methods, are autodigestive in character and more or less finite in extent. During steeping of the seed, water enters freely into the inner endosperm tissue, and what happens it is wellnigh impossible to outline. The net result is apparently a reduction in its enzyme content as shown by subsequent digestion, but, on the other hand, during steeping of the intact seed the secretory 
mechanism of the aleurone layer is at once set in motion. Its activity during these apparently and outwardly passive phases of activity are, however, distinctly intracellular, i. e. little or no enzyme is excreted into the subjacent tissue, and consequently a heaping up of enzyme and its possible precursors takes place within its cells as shown by predigestion of papain at this stage.

The experimental results, in short, bear out the work of Ford and Guthrie, and show that predigestion with papain under the modified conditions here employed results in an enhancement of the amyloclastic capacity of the material under investigation.

The absolute amylase content or amyloclastic activity of a given plant or seed tissue or organ cannot of course be determined, yet it must be conceded that its value must be finite. The method of papain-digestion described as applied exclusively ${ }^{1}$ to the investigation of the amyloclastic capacity of ungerminated barley furnishes greatly enhanced values as compared with those afforded by other methods so far examined, and apparently these values are of the nature of limiting values.

As such, they may be legitimately utilized as a tentative basis for the approximate calculation of the amount of amylase initially present as preexistent or 'free' and 'latent' amylase respectively, and the amounts of amylase which are contributed by the 'secretory' epithelium and aleurone layer at certain stages of germination.

\section{Investigation of material from germinated seeds by direct, auto-, and papain-digestion methods.}

One of the principal features so far presented is the very considerable divergence in the value of the amylase content of the structural parts of the endosperm of the ungerminated seed as separately determined by these methods of determination.

Does this differential feature still hold when similar structural parts from seeds after varying periods of germination are similarly examined?

The question can be efficiently considered only by an appeal to direct experiment.

Throughout, the experimental work described in this subsection refers to the examination of material prepared from seeds which, after the customary preliminary sterilization, were germinated in moist sand in Coldewe germinators at the temperature of the laboratory $\left(\mathrm{I} 5^{\circ} \mathrm{C} .-18^{\circ} \mathrm{C}\right.$.).

The seeds after the removal from the germinators were at once dissected into embryos, aleurone layers, and inner endosperms, and afterwards desiccated at $30^{\circ} \mathrm{C}$. for ten to twenty hours. The separate examinations of the amyloclastic capacities of the material by the three methods, the

1 Papain-digestion does not, as we shall see, influence the amyloclastic capacity of the growing embryo of barley nor that of Tropacolum or its structural parts. 
subsequent determinations of the copper-reducing values, and the method of expressing the results, are precisely identical with those already cited.

In the following table are shown the results derived from the estimation of intact seeds after three and a half to six days' germination :-

\section{TABLE XLV.}

Amylase Content of Intact Germinated Seeds.

\begin{tabular}{|c|c|}
\hline Digestion method. & $\begin{array}{l}\text { Germination period. } \\
3 \frac{1}{2} \text { days. } 6 \text { days. } \\
\text { Amylase per } 20 \text { objects per hour } \\
\text { (equivalent to mg. Cu). }\end{array}$ \\
\hline $\begin{array}{l}\text { Papain } \\
\text { Auto }\end{array}$ & $\begin{array}{lr}7682 & 9001 \\
5664 & \text { I016I }\end{array}$ \\
\hline Direct & 5044 \\
\hline
\end{tabular}

There is, as the above values show, a decided tendency as germination progresses for the values of the amylase content of the seed taken as a whole to converge; at the end of three and a half days the divergence as exhibited by material from air-dried or steeped seeds is very considerably diminished ; at the end of six days the values are of practically the same order of magnitude, such divergence as is still existent being almost certainly due to the individuality of the seeds taken for examination.

The results comprised in the table which follows throw some light on the relative distribution of amylase in the structural parts of the seed, and moreover indicate where the divergence mainly exists, namely, in the inner endosperm tissue.

The interesting fact, exemplified not only here but in the table which follows, is brought to light, i.e. that the amyloclastic capacity of the embryo is greatest as measured by the direct method of digestion; the values afforded by the aleurone layer tend to approximate, and those for the whole seed, whether determined by direct experiment or calculation, also show a similar tendency.

\section{TABLE XLVI.}

\section{Amylase Content of (a) Structural Parts from Germinated Seeds, $(b)$ Intact Germinated Seeds.}

Germination period, 4 days.

\begin{tabular}{|c|c|c|c|c|c|}
\hline $\begin{array}{l}\text { Digestion } \\
\text { method. }\end{array}$ & $\begin{array}{l}\text { Embryos. } \\
\text { Am }\end{array}$ & $\begin{array}{l}\text { Aleurone } \\
\text { layers. } \\
\text { lase per } 2 \\
\text { equivalen }\end{array}$ & $\begin{array}{l}\text { Inner } \\
\text { endosperm } \\
\text { objects per } \\
\text { to } \mathrm{mg} \text {. Cu) }\end{array}$ & Total. & $\begin{array}{l}\text { Intact seeds. } \\
\text { Amylase per } 20 \text { objects per hour } \\
\text { (equivalent to } \mathrm{mg} . \mathrm{Cu}) \text {. }\end{array}$ \\
\hline Papain & $23^{2}$ & 2405 & 8924 & II $56 \mathrm{I}$ & 10550 \\
\hline Auto & 310 & 2560 & $574^{2}$ & $86 \mathrm{I}_{2}$ & 8846 \\
\hline Direct & 465 & $155^{2}$ & 4190 & 6207 & $675^{\mathrm{I}}$ \\
\hline
\end{tabular}

A repetition of these characteristic features is shown by the experimental data embodied in the table which follows :- 


\section{94 Stoward.-Amyloclastic Secretory Capacities of the}

\section{TABLE XLVII.}

\section{Amylase Content of $(a)$ Structural Parts of Germinated}

Seeds, $(b)$ Intact Germinated Seeds.

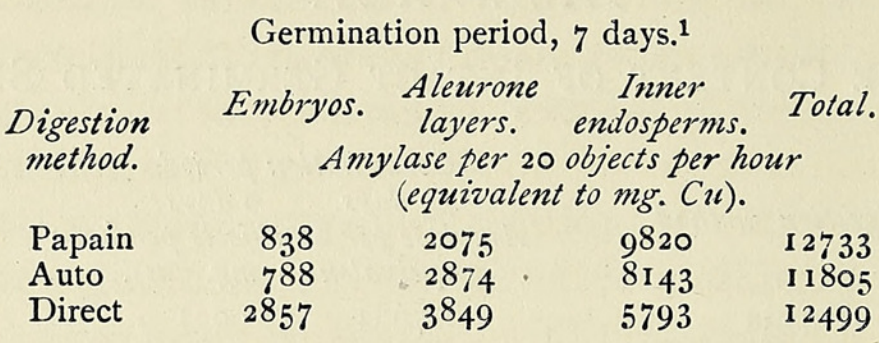

The inverse order of the magnitude of the results in the case of embryos and aleurone layers, and the convergence of results as regards the inner endosperm, are again demonstrated.

The general conclusion to be deduced from these essays is that the marked divergence in the amyloclastic capacity possessed by air-dried and steeped seeds, and material derived from them, following the method of digestion employed, tends to disappear, as shown by parallel investigations of similarly prepared germinated seed material from them.

The other outstanding fact of significance is that papain-digestion is responsible for lower results than direct digestion in the case of embryos and aleurone layers.

A short survey of the results furnished by the data as determined by papain-digestion, comprised in the foregoing tables, relative to the amyloclastic capacity of the intact seed, whether determined by experiment or arrived at by calculation, will suffice to show the few deductions of importance concerning the question of the sources of the amylase present or of the relative amounts of amylase in the inner endosperm.

When, however, we turn to the data derived from the separate examination of the amyloclastic capacity of the anatomical parts of the endosperm taken from the seed at various stages, during the progress of germination, important conclusions may, if certain assumptions are made, be put forward.

We have seen that papain-digestion, if it does not afford a means of arriving at the maximal amyloclastic capacity of the inner endosperm, at least furnishes what appears to be the 'limiting' values for that capacity, and as such we may with justification employ it tentatively as a basis in an

1 Investigation of the inner endosperm tissue beyond this stage is rendered irregular and uncertain by reason of the loss of a considerable portion of substance during desiccation on absorbent paper. This applies to circumstances in which the progress of the germinative processes has reduced the residual tissue to a semi-fluid mass. Moreover, at this point considerable diminution of material arises through exercise of the absorptive functions of the embryo. 
attempt to evaluate the amounts of amylase which are contributed by the embryo and aleurone layer during the phases of germination cited in the preceding tables.

The inner endosperm during the progress of germination is regarded as the recipient of amyloclastic enzymes which arise as secretions of the embryo (scutellar epithelium) and aleurone layer, both of which tissues have been shown by direct experimental evidence to be glandular in function.

The inner endosperm possesses the capacity of augmenting its amylase content. The tissue is probably non-living, and is unable to deplete itself. This phenomenon occurs indubitably when the aleurone layer forms an integral part of the endosperm, but does not when the vital activity of the aleurone layer is annulled, and these supplementary facts are regarded as supporting the assertion that the aleurone layer is living and secretes the enzyme which principally conditions depletive change. Other experimental evidence points to the same conclusion. The assumption, therefore, that part of the amylase found in the inner endosperm is secreted and excreted by the aleurone layer receives justification, and similarly it can be demonstrated that the embryo also contributes a share.

If we assume that the papain-digestion value for the inner endosperm, after removal from the steeped seed, furnishes the limiting value of its amyloclastic capacity, and further assume that it represents its finite augmentative capacity (an assumption justified by the evidence adduced for regarding it as not representing a living tissue), then we can calculate approximately, from the increase of amylase which takes place in this tissue during certain phases of the germinative process, the relative amounts of amylase derived from the combined secretory activities of the embryo and aleurone layer. These are shown in the following table :-

\section{TABLE XLVIII.}

\section{Relative Amounts and Sources of ORigin of Amylases PRESENT IN INNER ENDOSPERMS OF Germinated SEed.}

Papain-digestion.

Amylase initially present in
inner endosperm from steeped
seed.

(I)

5000

5500
Amylase present in inner endosperm after days of germination.

Amylase per 20 objects (equivalent to $\mathrm{mg}$. Cu).

\section{(2)}

4 days 8900

7 days 9800
Amylase derived from embryo and aleurone layer.

The values given under columns (I) and (2) represent the amounts of enzyme, as determined by papain-digestion, present in the inner endosperm initially, and after four and seven days' germination respectively. The 
amount of enzyme in the inner endosperm of the germinated seed is taken as the sum of that furnished by this tissue, plus that derived from the embryo and aleurone layer. The values given in the final column (3) are the differences obtained by subtracting the values of column (I) from column (2). The amounts of amylase contributed by the aleurone layer and embryo calculated on this basis are by no means insignificant, for they amount to roughly $45-55 \%$ of the amylase present in the inner endosperm taken at the periods of germination indicated.

The assumption has been tacitly made, however, that the amylase of the inner endosperm and that derived from the aleurone layer and embryo are identical in their nature and amyloclastic attributes, and it has been further assumed that the amylase which originates in the inner endosperm undergoes no reduction in amount as the result of its activity. This cannot, however, be regarded as correct in the light of the experimental evidence afforded by the study of the action in situ of the enzyme, which is preexistent and accumulates in the inner endosperm, or of their behaviour towards gelatinized starch. In short, the inner endosperm appears to be an exchequer which receives enzymatic contributions from the active secretory tissues, and also possesses the power of augmenting its enzyme content autonomously. But the currency it receives is of more value, especially as far as its internal transactions are concerned, than that which it originates itself, and for this reason estimations of the amount of amylase a tissue (such as the inner endosperm) is capable of augmenting are of subordinate significance in relation to the question of endospermic depletion, unless it can be definitely shown that the enzyme possesses a capacity of attacking the starch reserves placed at its disposal, equal or superior to that possessed by the 'secretion' variety elaborated by the embryo and aleurone layer.

The estimates given of the contributory share derived from the aleurone layer and embryo are by no means over-estimated, for there is evidence to show that the amylase of the inner endosperm, when it does manifest its comparatively feeble powers of attack on endospermic starch grains, probably undergoes either inactivation or destruction. And if this phenomenon also takes place in the inner endosperm during the march of the germinative processes, then the amounts of enzyme contributed by the veritable secretory tissues (the scutellar epithelium and aleurone layer) are probably greater than those given in the above table; in other words, the values given tend to under- rather than over-estimate the amount of amylase from these sources. 


\section{Investigation of Amylase Content of the Tissues of Tropaeolum by Direct, Auto-, and Papain-Digestion METHODS.}

Determinations of the amyloclastic capacity of embryos (seedlings) and aleurone layers from barley at certain stages of germination having shown, contrary to the experience with ungerminated barley, that autoand papain-digestions of these objects invariably gave lower values than by the direct method of digestion, at once raised the question whether the amylase present in the tissues of a typical phanerogamous plant, such as Tropaeolum, and presumed to consist wholly of the 'translocation' variety, would comport itself in a similar fashion. If so, then certain considerations might with justification be advanced regarding the possible nature and conditions of existence of the pre-existent amylase or its possible antecedent in the inner endosperm of the grain of barley.

A quantity of freshly gathered plants of Tropaeolum were procured, dissected into petals, stems, and roots, ${ }^{1}$ desiccated for forty-eight hours at $30^{\circ} \mathrm{C}$., and afterwards separately investigated for amylase by the direct, auto-, and papain-digestion methods.

Experimental and corresponding control digestions were carried out as follows :-

The desiccated material was first finely pulverized in a mortar, then passed through a finely-meshed horsehair sieve, and quantities of material taken from the bulk of $0.3 \mathrm{grm}$. were placed in each of a series of conical Jena flasks and afterwards Io c.c. of either plain distilled water (autodigestion) or of a $0.5 \%$ or I \% solution of papain (papain-digestion) were pipetted into each flask.

The flasks and their contents were then placed in a thermostat at $30^{\circ} \mathrm{C}$, and after the addition of an antiseptic and tightly corking, the predigestion was continued for twenty hours.

The contents of the control predigestions were then arrested by boiling, cooled, brought to the temperature of the thermostat $\left(30^{\circ} \mathrm{C}.\right)$, a fresh addition of antiseptic made, and I5 c.c. of soluble starch solution (equivalent to 25 c.c. at $3 \mathrm{grm}$. starch solids per Ioo c.c. of solution) were added to both experimental and control flasks, and the starch digestions thus established were continued for twenty hours at $30^{\circ} \mathrm{C}$.

A similarly constituted series of experimental and control digestions (direct digestions) were carried out simultaneously with the above by adding directly 25 c.c. of $3 \%$ starch solution to each $0.3 \mathrm{grm}$. of finely-

1 Brown and Morris: Chemistry and Physiology of Foliage Leaves. Journ. Chem. Soc., 1893, vol. 63, p. 634. After desiccation the stock material was conserved in a desiccator over $\mathrm{H}_{2} \mathrm{SO}_{4}$. 


\section{98 Stoward.-Amyloclastic Secretory Capacities of the}

ground tissue; the time and temperature of digestion being identical with those of the preceding series, viz. twenty hours at $30^{\circ} \mathrm{C}$.

Finally, experimental digestions in all the series were arrested by boiling their contents, care being taken subsequently, in those in which chloroform served as the antiseptic, to expel this reagent. After cooling, diluting to Ioo c.c., and filtering, duplicate copper reductions were carried out on the filtrates in the usual manner.

The following table comprises the results yielded by digestions of the leaves of the plant :-

\section{TABLE XLIX.}

Amylase Content of Petals of Tropaeolum.

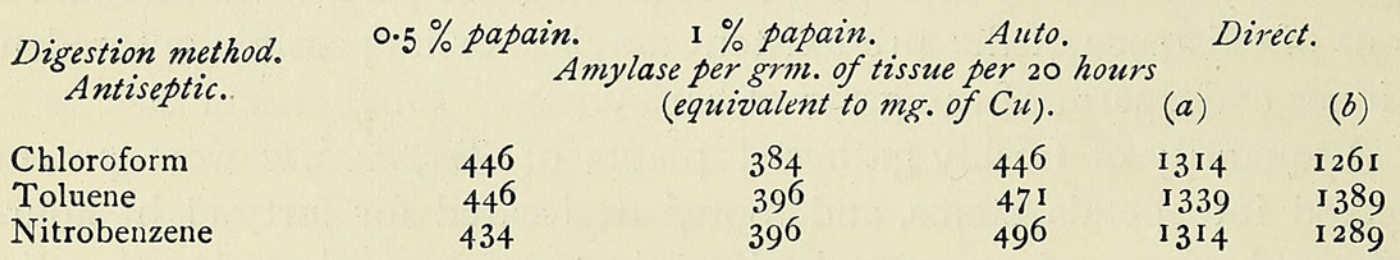

The experimental conditions, as the above table indicates, were varied by the employment of three different antiseptics and two different concentrations of papain. Direct-digestion results were so markedly different in order of magnitude from those of the other methods that a second series (b) was carried out in order to be doubly sure of the result.

Obviously the amylase in an actively metabolizing tissue like that of the plant examined does not presumably exist in the latent condition. The behaviour of the enzyme under the conditions introduced by digestion with papain appears to parallel those found in the case of the seedling and the aleurone layer of barley seed during the advance of the germinative processes.

The greatest divergence occurs in the case of the leaf tissues, as the following results, carried out under experimental conditions identical with those in the preceding experiments, show.

Whether, after the tissue has passed the heyday of its existence, papain-digestion would induce enzymatic augmentation, as it apparently does in the case of the endospermic substance of ungerminated barley, or whether the conditions provided by the leaf tissues per se as in direct digestion are superior to those provided by papain, must remain a question for future research to determine. 


\section{TABLE L.}

\section{Amylase Content of Mixed Root, Stem, and Leaf- STRUCTURES OF TROPAEOlum.}

$\begin{array}{lcc}\text { Digestion method. } & \text { Antiseptic. } & \text { Amylase per grm. of tissue per } 20 \text { hours } \\ \text { (equivalent to mg. of } C u \text { ). }\end{array}$

Amylase content of Tropaeolum stems.

$\begin{array}{lccc} & & (a) & (b) \\ \text { Papain } 0.5 \% & \text { Chloroform } & 5 \text { OI } & 448 \\ \text { Direct digestion } & \text {, } & 8 \mathrm{I} 7 & 975\end{array}$

The primary deduction to be drawn from these results is that the condition of existence of the amylase, especially in the leaf-tissue of Tropaeolum, which we may justifiably assume is the 'translocation' variety, and that in the reserve system of the barley grain are materially different. Papain-digestion of the tissues of Tropaeolum, unlike papaindigestion of the inner endosperm of the air-dried or steeped seed of barley, does not lead to an increase but to a decrease of amylase, and if we assume that the special function of papain is to release the 'latent' amylase existent in a tissue, then it appears to be permissible to conclude that in actively metabolizing tissues, such as those of Tropaeolum, the amylase present exists entirely in the 'free' condition, the term 'free' implying that practically the bulk of the enzyme present is unmasked by direct digestion, and that papain-digestion of such a tissue fails to afford higher results than those furnished by direct digestion.

The term 'latent' enzyme, as employed by Ford and Guthrie, implies that a certain proportion of the enzyme existent in the mature inner endosperm cells of barley presumably becomes associated with a protein complex from which apparently it must be dissociated before it can manifest its active powers.

During the course of the present investigation, other points of view have presented themselves regarding the nature of the 'latent' enzyme of the inner endosperm. The chief function of the amylase existent in the endosperm of barley during the development and maturation of the grain relates to the translocation of starch from one cell of the endosperm to another. When the grain reaches maturity the enzymes and reserves are immobilized, and a considerable proportion of the amylase then probably undergoes a series of changes of which 'latent' amylase represents only a phase.

It seems probable, judging from the comparatively feeble capacity the amylase of the inner endosperm has of attacking any other than the small immature starch grains, the feeble auto-depletive powers of the 
inner endosperm, the dead nature of this tissue, and its finite enzymeaugmentative capacity, \&c., that the 'latent' enzyme of the barley-endosperm may actually represent an enzyme undergoing step by step a series of complex retrograde changes, the final terms of which may be simply the more or less complex protein reserves of the inner endosperm. If such a view be correct, then the 'latent' amylase of this tissue represents an enzyme which has undergone partial retrogradation, i.e. a complex, one portion of which consists of unchanged amylase, the other of amylase which has undergone transformation into protein reserve substances.

The view propounded merely attempts to suggest a possible explanation of the results which follow on predigestion of the inner endosperm with papain, and to hint at the possible mode of origin of the 'latent' amylase of the resting grain of the inner endosperm.

The results recorded in this section show, at least, that papaindigestion as a means of determining the higher limiting value of the amylase content of a given tissue is not of universal application.

The results are in no way equivocal ; direct digestion in all cases yields results which are superior in order of magnitude to those furnished by papain-digestion.

\section{Summary of Conclusions.}

The whole of the experimental work described in this paper, comprising an investigation of

(I) the separate amyloclastic secretory capacities of the embryo and aleurone layer ;

(2) the amylase augmentative and depletive capacities of the endosperm and inner-endosperm; and

(3) the demonstration of the possession of a cytoclastic secretory capacity for the embryo and aleurone layer of the seed of Hordeum,

has been carried out with the sterilized objects and under rigidly aseptic conditions. Throughout, the aim has been to measure quantitatively the amyloclastic capacities of the three principal anatomical parts of the seed (embryo, aleurone layer, and inner endosperm), in order to ascertain as far as possible the (I) sources of origin of the amylases which accumulate in the inner endosperm during the progress of the germinative processes, (2) their relative magnitudes, and (3) the shares the amylases which are elaborated or generated in these tissues take in the digestion of the starch reserves stored in the inner endosperm.

The following conclusions appear to be justified by a general survey of the results furnished by this investigation :-

I. Direct experimental investigation of the amyloclastic secretory 
capacities of isolated embryos, aleurone layers, and endosperms, and also of the amyloclastic generative capacity of the inner endosperm of Hordeum, by means of cultures of these objects on variously constituted media and substrata, and subsequent determination of the amounts of amylase in the culture medium and objects or of the products of amyloclastic action, shows-

(a) Both embryos and aleurone layers possess an amylo- and a cytoclastic secretory function.

(b) These secretory functions are completely arrested and annulled when these objects are subjected to the action of anaesthetic reagents such as chloroform and nitrobenzene. This result, in the case of the aleurone layer, is regarded as evidence that this tissue possesses vitality.

(c) The inner endosperm, under varying conditions of experiment described, possesses the capacity of augmenting its amylase content. This augmentative capacity, however, does not represent a process of veritable secretion (the amyliferous cells are not secretory in function), and, in contradistinction to the secretory capacities of the embryo and aleurone layer, is not arrested or diminished by the action of chloroform or nitro. benzene. This latter fact, viz. the capacity of a tissue to augment its enzyme content as readily and to the same (or a greater) extent both in the presence and absence of reagents which are acknowledged to be fatal to living protoplasm, is taken to signify that $(\mathrm{I})$ the inner endosperm represents a mass of non-living tissue, and that (2) its behaviour under the conditions described is such as a dead mass of enzyme-containing tissue would exhibit.

2. Comparative experiments with isolated endosperms and inner endosperms under identical conditions of experiment, ample provision being afforded for the ready outward diffusion of the products of digestive action, show that-

(a) Isolated endosperms possess the capacity of inducing the complete auto-digestion and auto-depletion of their storage contents, the phenomena observed being the gradual reduction of the mass of the inner endosperm, the appearance of reducing carbohydrates in the experimental substratum, dissolution of cell walls and cytoplasm of the amyliferous cells, ready separation of the aleurone layer from the sub-aleuronic tissue, and characteristic erosive dissolution of the starch grains.

(b) Isolated inner endosperms are incapable of inducing auto-digestive and auto-depletive processes in any way comparable with those observed in the case of endosperms, the phenomena observed 
resulting in a very small reduction in the mass of the inner endosperm and the appearance of smaller amounts of reducing sugars in the culture substratum. There is, moreover, an entire absence of any obvious evidence of cell-wall or cytoplasmic disintegration, and the dissolution of starch, which appears to be confined to the more minute grains, is unaccompanied by any signs of erosive dissolution.

Although augmentation of amylase invariably occurs in both types of objects, that of the endosperm is superior to that of the inner endosperm ; yet in the former complete depletion occurs, while in the latter it only advances to a stage which falls very far short of complete depletion. In other words, no proportionality or apparent relationship exists between the enzyme-augmentation capacity of the inner endosperm and the amount of self-digestion it is capable of inducing in its starch reserves as they exist in situ.

The capacity which a tissue such as the inner endosperm may possess of augmenting enzyme in its cells is of subordinate importance for the question of endospermic depletion, unless it can be shown that the enzyme it generates is capable of attacking the starch reserves as they exist in situ in the inner endosperm of the steeped seed. The fact that the amylase of the resting grain or of the inner endosperm of the steeped seed (which are regarded as being identical) readily liquefies and hydrolyses starch paste cannot be accepted as a criterion of the possible rôle this enzyme may play in endospermic depletion.

3. Comparative experiments with endosperms and inner endosperms subjected during the entire period of culture to the action of chloroform or nitrobenzene, and .comparison of the results with those of similarly conducted non-anaesthetized objects (cf. 2), demonstrate very clearly that-

(a) the augmentation of amylase by the endosperm undergoes marked reduction, being reduced to the same order of magnitude as that of the inner endosperm;

(b) the augmentation of amylase by the inner endosperm is unaffected, $i$, e. it is of the same order of magnitude as that of nonanaesthetized inner endosperms ;

(c) anaesthetized endosperms, unlike non-anaesthetized endosperms, are incapable of inducing complete auto-depletion of their reserve storage materials. There is an entire absence of erosive dissolution of starch grains, of cytoclastic action; the aleurone layer remains closely adherent to the underlying tissue, and the amounts of reducing sugars found in substrate and objects are of the same order of magnitude as in experiments with anaesthetized and non-anaesthetized inner endosperms.

The above results are interpreted as being directly due to the 
suppression of the secretory functions of the aleurone layer, and are regarded as confirmatory of the experimental evidence furnished by direct examination of the secretory functions of the isolated aleurone layer.

In short, endospermic depletion, as it occurs in the intact seed, is principally conditioned by the action of enzymes secreted by the aleurone layer and embryo; in the isolated endosperm, by the aleurone-layer secretions, and in both cases the principal rôle is due to the aleurone layer ; the amyloclastic enzyme pre-existent in the inner endosperm and that which it generates is adjunctive.

4. The amyloclastic enzymes secreted by the embryo and aleurone layer are identical, and are distinct from that existent and generated by the inner endosperm.

The columnar epithelial and aleurone-layer cells, although morphologically different, possess similar physiological functions. The view, based on this fact, is advanced:- the aleurone layer is the analogue of the columnar epithelium, and this analogy suggests that the endosperm of Hordeum represents an abortive or undifferentiated embryo, and consequently, on biochemical grounds, the phenomenon of 'double fertilization' or 'triple fusion' possibly occurs in Hordeum.

5. Both auto- and papain-digestion of ungerminated barley substance lead to considerable augmentation of its amylase content or its amylolytic activity over and beyond that which follows on direct digestion.

Similarly conducted comparative digestion experiments with material from intact seeds and with material from seeds placed under germination conditions show that-

(I) The values of the amylase content of intact seeds as determined by the three methods of digestion tend to converge as the period of germination advances.

(2) The values of the amylase content of parts of the seed as determined

by the three methods of digestion vary. Thus :-

(a) the embryo throughout gives higher values by direct than by either papain- or auto-digestion;

(b) the aleurone layer at first gives lower and afterwards higher values by the direct method of digestion;

(c) the inner endosperm throughout gives lower values by the direct method, but the divergence of results tends to diminish as germination proceeds.

Examination of the amylase content of the leaf and other organs of Tropaeolim by the three methods of digestion shows that the direct method invariably yields higher results than either the papain- or auto-digestion method. This result implies that in actively functionary tissues as opposed to the reserve storage organ of Hordeum, the amylase is present wholly in the 'active' or 'free' condition, and further indicates that papain-digestion, 
I 204 Stoward.-Amyloclastic Secretory Capacilies of Hordeum.

as a means of determining the amylase content of a plant organ or tissue, is probably not of wide application.

6. Cane sugar inhibits the secretion of amylase by the embryo, dextrose diminishes it, but invert sugar has apparently no influence on the phenomenon.

7. The suggestion that the amylase which arises as secretions of the embryo and aleurone layer may activate that of the inner endosperm is not supported by experimental evidence.

In conclusion, I desire to express my deep thanks to Professor Adrian J. Brown, F.R.S., for his generous and helpful advice, guidance, and criticism, and also for the many facilities he has afforded me during the conduct of this investigation. My best thanks are also due to Messrs. T. H. Pope, B.Sc., and Ch. Evans, B.Sc., who have been good enough from time to time to offer many valuable suggestions and criticisms.

Department of the Biology and Chemistry of Fermentation, UNIVERSITY OF BIRMINGHAM. 


\section{$2 \mathrm{BHL}$ Biodiversity Heritage Library}

Stoward, Frederick. 1911. "A research into the amyloclastic secretory capacities of the embryo and aleurone layer of Hordeum with special reference to the question of the vitality and auto-depletion of the endosperm. Part II." Annals of botany 25, 1147-1204. https://doi.org/10.1093/oxfordjournals.aob.a089367.

View This Item Online: https://www.biodiversitylibrary.org/item/239487

DOI: https://doi.org/10.1093/oxfordjournals.aob.a089367

Permalink: https://www.biodiversitylibrary.org/partpdf/319882

\section{Holding Institution}

Smithsonian Libraries

\section{Sponsored by}

Biodiversity Heritage Library

\section{Copyright \& Reuse}

Copyright Status: Not in copyright. The BHL knows of no copyright restrictions on this item.

This document was created from content at the Biodiversity Heritage Library, the world's largest open access digital library for biodiversity literature and archives. Visit BHL at https://www.biodiversitylibrary.org. 